ISSN: 0514-7336 — ISSN electrónico: 2386-3943

DOI: https://doi.org/10.14201/zephyrus202085185206

\title{
UNA NECRÓPOLIS POSTIMPERIAL DE LA VILLA DE ALMENARA DE ADAJA-PURAS (VALLADOLID)
}

\section{A post-imperial necropolis of the Roman villa of Almenara de Adaja-Puras (Valladolid)}

\author{
Carmen García-Merino* y Margarita SánCheZ-Simón** \\ * Dpto. de Prehistoria, Arqueología, Antropología Social y CC. y TT. HH. Univ. de Valladolid. Plaza del Campus, s/n. \\ 47011 Valladolid. Correo-e: mariacarmen.garcia.merino@uva.es. ID ORCID: https://orcid.org/000-002-2312-8088 \\ ** Facultad de Humanidades y Comunicación. Paseo de Comendadores, s/n. 09001 Burgos. Correo-e: \\ margaritasanchezsimon@gmail.com.ID ORCID: https://orcid.org/0000-0002-8426-8447
}

Recepción: 26/06/2019; Revisión: 14/07/2019; Aceptación: 28/04/2020

Resumen: Se presenta un pequeńo conjunto de 10 tumbas situado en las inmediaciones de la villa de Almenara de Adaja-Puras. Esta área cementerial corresponde a un grupo humano relacionado con la última fase de la actividad en esta villa, cuando alrededor de la pars urbana se dispuso una serie de construcciones de tipo rústico que estuvieron en uso hasta avanzada la segunda mitad del s. v d. C. Se analizan varios aspectos de esta necrópolis, entre ellos la población enterrada y la caracterización del depósito funerario y/o del ritual. Así mismo se incide sobre la organización interna y su expolio, lo que ha permitido reconocer diferentes momentos de uso en época tardoantigua. Como rasgos más destacables de estas inhumaciones en fosa destacan la escasez de ajuares y de recipientes para el banquete fúnebre, el empleo de ataúdes y la presencia de calzado ritual depositado a un lado de los pies. Se han identificado varias tumbas que presentan una mayor complejidad constructiva; entre ellas hay una que cuenta con mensa, algo que resulta lo inhabitual en la zona septentrional de Hispania.

Palabras clave: Tardoantigüedad; cementerio rural; ataúd; depósito funerario; calzado ritual; expolio; tumba con mensa.

AвSTRACT: We present a small group of 10 tombs located in the vicinity of Almenara de Adaja-Puras villa. This cemetery area corresponds to a human group related to the last phase of the activity in this Roman villa, when around the urban pars was arranged a series of constructions of rustic type that were in use until advanced the second half of the $\mathrm{v}^{\text {th }}$ century AD. Several aspects of this necropolis are analyzed, among them the buried population and the characterization of the funerary deposit and/or the ritual. The internal organization and its despoilment are also emphasized, which has made it possible to recognize different moments of use in the Late Antiquity. The most outstanding features of these burials in graves are the lack of trousseaux and containers for the funeral feast, the use of coffins and the presence of ritual footwear deposited on one side of the feet.

Key words: Late Antiquity; rural cemetery; coffin; funerary remains; ritual shoes; pillage; mensa tomb. 


\section{Introducción}

La villa romana tardía de Almenara de Adaja-Puras (La Calzadilla), intervenida parcialmente entre 1942 y 1993, ha sido con posterioridad objeto de un proyecto de excavación integral, restauración y apertura al público desarrollado entre 1999 y 2003 (García-Merino y Sánchez-Simón, 2015: $27-$ 28). Más tarde, a partir del hallazgo en 2010 de una tumba durante unas obras en el parque infantil anejo (García-Merino y Sánchez-Simón, 2011), se ha documentado al $\mathrm{N}$ del edificio residencial, y a corta distancia de él, un grupo de enterramientos (Fig. 1) que ha dado lugar al desarrollo de un proyecto de investigación conjunto vinculado al Museo de las Villas Romanas de Almenara-Puras y a la Univ. de Valladolid entre 2013 y 2017, que ha posibilitado la completa excavación de ese pequeńo cementerio (Fig. 2) que cuenta solo con 10 tumbas $^{1}$.

En este trabajo ofrecemos un estudio sobre varios aspectos de esta necrópolis, entre ellos, de la población enterrada, de la caracterización del depósito funerario, del ritual y de la identificación de diferentes momentos de uso del cementerio en época tardoantigua. Además de los datos que presentamos, está en curso, en unos casos, o pendiente de publicación, en otros, una serie de análisis a cargo de diferentes especialistas cuyos resultados, cuando se den a conocer, complementarán la información que ahora adelantamos en aspectos tales como la caracterización paleopatológica y

García-Merino, C. y Sánchez-Simón, M. (2013): Sondeos arqueológicos en la necrópolis tardorromana de la villa romana de Almenara de Adaja-Puras (Valladolid); (2014): Sondeos arqueológicos en la necrópolis tardorromana de la villa romana de Almenara de Adaja-Puras (Valladolid). Campaña de 2014; (2015): Sondeos arqueológicos en la necrópolis tardorromana de la villa romana de Almenara de Adaja-Puras (Valladolid). Campaña de 2015; (2017): Sondeos arqueológicos en la necrópolis tardorromana de la villa romana de Almenara de Adaja-Puras (Valladolid). Campaña de 2017. Todos estos informes técnicos inéditos se encuentran depositados en la Junta de Castilla y León y en el Museo de las Villas Romanas de Almenara-Puras, donde están disponibles para su consulta. genética de los individuos inhumados, así como su alimentación ${ }^{2}$.

Lógicamente no sería este el único cementerio de este complejo yacimiento, pues el solar donde se ubica tiene una prolongada trayectoria habitacional y evidencias de instalaciones de tipo villa ya desde el s. III. En efecto, la secuencia de ocupación del paraje donde se encuentra la villa de Almenara de Adaja-Puras es muy larga y -ciñéndonos a la época histórica- hay evidencias de hábitat rural al menos desde época tardoaugústea. La ocupación de la zona continuó, constatándose mediante la fotografía aérea estructuras compatibles por su planta con la pars urbana de una villa probablemente ya en la tercera centuria. En el s. IV y a corta distancia al NE de esos restos, se construyó otra villa, que es visitable, de la que se han excavado toda el área residencial y parte de sus instalaciones rústicas, sin que podamos saber por ahora si coincidió con la otra algún tiempo o la sucedió. Este palacio tardío y las instalaciones de la explotación agropecuaria anejas estuvieron ocupadas entre la segunda mitad del s. IV y aproximadamente mediados del v, cuando surgió alrededor del edificio residencial ya deshabitado por sus dueños una serie de construcciones de tipo rústico, incluida al menos una vivienda íntegramente exhumada, que estuvieron en uso hasta avanzada la segunda mitad de esa misma centuria, momento en el que se abandonaron, desplazándose el hábitat al contiguo pago de La Vega-El Caballo. Es con esta fase tan avanzada de la ocupación en el yacimiento de

2 Se trata de los análisis de isótopos estables realizados por V. Pérez de Dios y A. Grandal d'Andrade, de la Univ. de A Coruña, para determinar aspectos de la dieta; los de P. Gelabert Xirinachs, del Instituto de Biología Evolutiva-CSIC, quien está estudiando el ADN a través de varias muestras dentales; y los de Zuriñe Sánchez-Puente, del Laboratorio de Evolución Humana de la Univ. de Burgos, que está analizando las dentaduras para obtener información complementaria sobre la alimentación de este grupo humano. Los estudios paleopatológicos, de los que en este artículo mencionamos algunos aspectos, están pendientes de publicación pormenorizada por parte del equipo de la Univ. de Valladolid dirigido por J. F. Pastor Vázquez. 


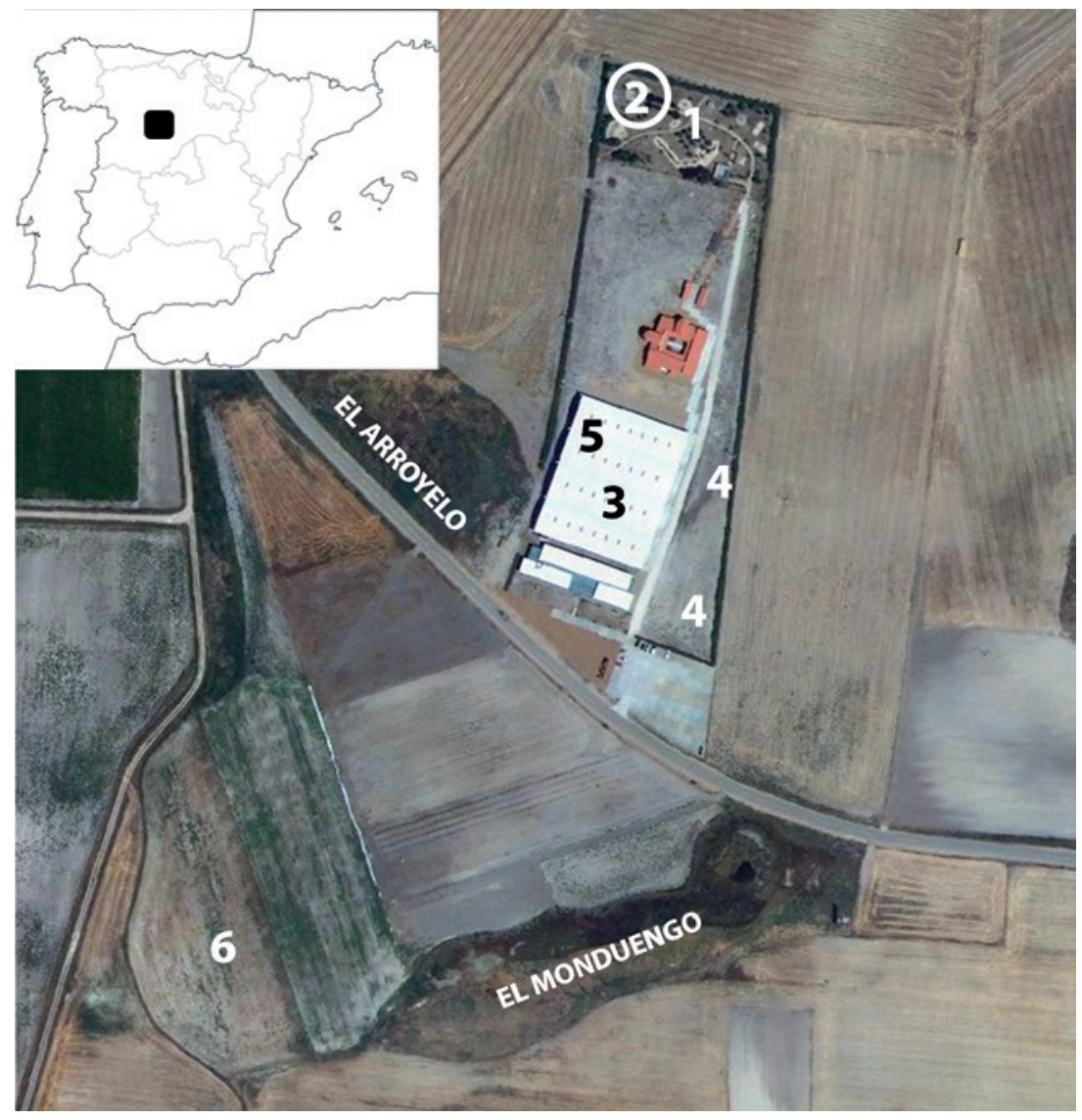

FIG. 1. Ortofoto del yacimiento arqueológico: 1) evidencias de hábitat de los ss. I y II; 2) necrópolis postimperial; 3) residencia tardoimperial y área de instalaciones rústicas datadas entre el s. III y mediados del IV; 4) alas rústicas tardoimperiales; 5) evidencias de hábitat algo posterior surgido en las inmediaciones; 6) evidencias de estructuras compatibles con una pars urbana del s. III-mediados del s. IV (sobre ortofoto: https://sigpac.magrama.es/fega/h5visor)).

sepulturas de que consta se distribuyen en cuatro calles orientadas en sentido E-O y equidistantes entre sí unos $2 \mathrm{~m}$. Las tumbas, con la cabecera hacia el $\mathrm{E}$, se disponen de tal manera que se pueden reconocer hasta cuatro alineaciones en sentido N-s. El espacio así organizado no se ocupó por completo, pues solamente son 10 los enterramientos efectuados que dejan entre ellos lotes sin usar; tanto es así que incluso en el borde más septentrional se identificó una fosa que no llegó a finalizarse. Muestra de esta baja intensidad en el uso del espacio cementerial es el hecho de que no se hayan identificado en ninguna de las fosas ni reutilizaciones ni acciones de reducción de huesos.

La necrópolis ha sido excavada por completo. En el extremo No del parque infantil, donde se ubica, se han abierto $300 \mathrm{~m}^{2}$ en los que se ha profundizado hasta alcanzar el nivel estéril ${ }^{3}$, revelando que se circunscribe solo a un pequeño sector. Gracias a los numerosos sondeos que se

Almenara de Adaja-Puras con la que relacionamos esta necrópolis (García-Merino y Sánchez-Simón, 2015; 2017: 179-181).

\section{La necrópolis postimperial}

\subsection{Descripción general y cuestiones cronoestratigráficas}

La necrópolis ocupa una pequeña extensión de aproximadamente unos $175 \mathrm{~m}^{2}$. Se localiza a escasos $200 \mathrm{~m}$ al no del palacio bajoimperial y del posterior hábitat rústico surgido en sus inmediaciones, del que es contemporánea (Figs. 1 y 2). Las diez han hecho tanto hacia el E como al N y s, se puede asegurar que no existen más enterramientos. Así, las sepulturas se localizan en una pequeña área de aproximadamente $175 \mathrm{~m}^{2}$ en la que al excavar se han identificado otras evidencias, gracias a las cuales se puede conocer la evolución diacrónica de este sector concreto del yacimiento. Así, en este lugar, durante las dos primeras centurias de la Era se dispusieron algunas construcciones con paredes de barro sobre cimientos de mampuestos calizos y/o cantos, cuyas estructuras arruinadas se sedimentaron a lo largo de los siglos posteriores. Bajo estos escombros se han

3 Las intervenciones arqueológicas se han desarrollado bajo la dirección de las autoras de este trabajo y con la 


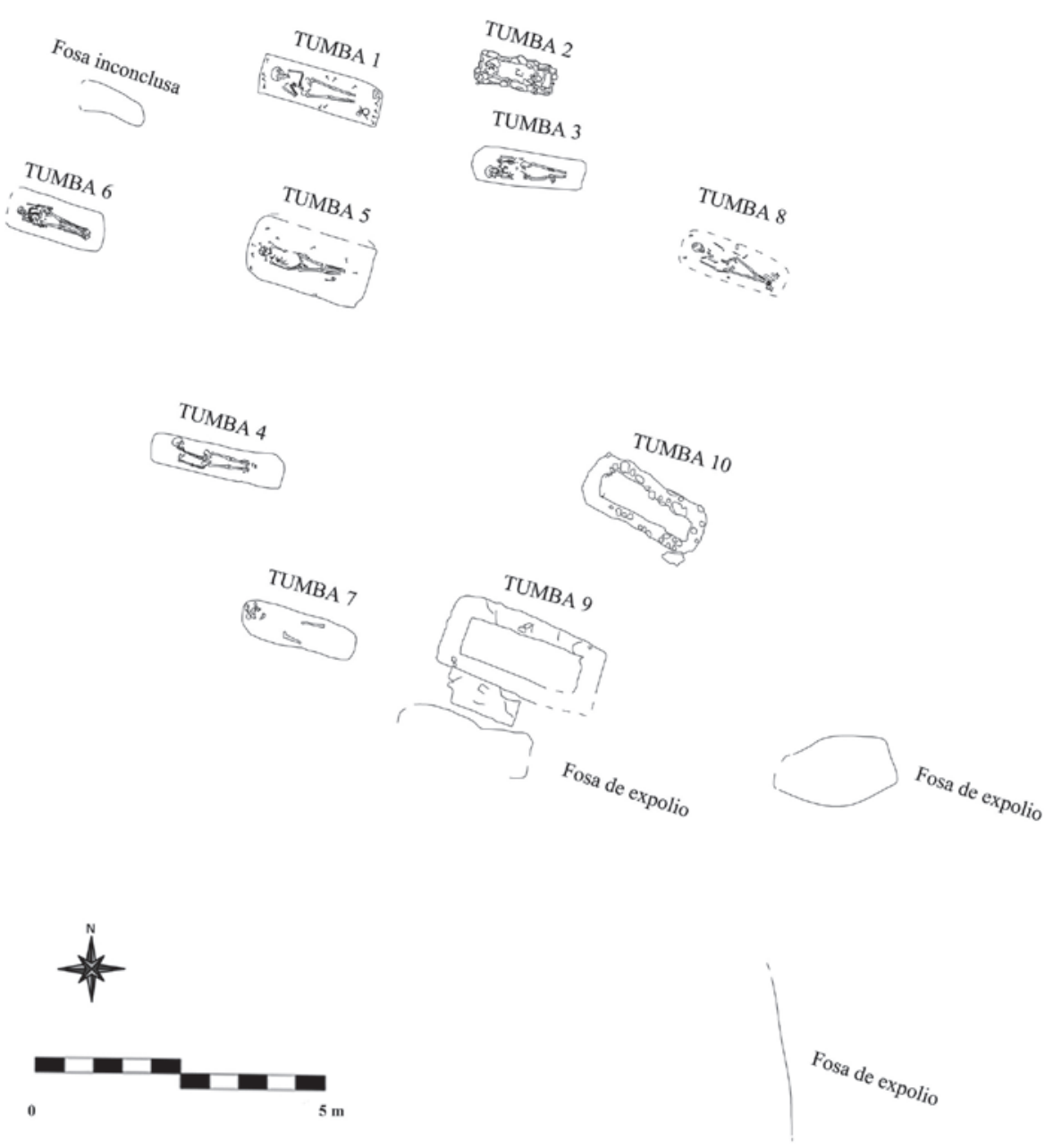

Fig. 2. Planta de la necrópolis postimperial de la villa de Almenara de Adaja-Puras.

con el paso del tiempo en un estrato de tierra de unos $20 \mathrm{~cm}$ de espesorllegando a la capa estéril infrayacente.

El borde superior de todas las tumbas se ha reconocido inmediatamente bajo el nivel afectado por el arado (Fig. 3). Desde esa cota, las sepulturas ahondan un mínimo de $30 \mathrm{~cm}$ -Tumba 2- y un máximo de 1,20 m -Tumba 4-. Gracias a que los esqueletos, ajuares y depósitos funerarios se encontraban a esa profundidad la conservación era excelente, como por otra parte se puede apreciar en las diferentes imágenes que ilustran este trabajo. Por la misma razón, por no haber sido removidas las tumbas por las tareas agrícolas, la estratigrafía arqueológica originaria estaba intacta, lo que nos permite reconocer que,

identificado algunas evidencias negativas que muestran ya uso doméstico de la zona en época altoimperial: un posible silo que no se finalizó y una fosa circular -de $40 \mathrm{~cm}$ de diámetro x 30 de profundidad-, probablemente contenedor de una tinaja para almacenar víveres. Siglos más tarde, ya avanzado el $\mathrm{v}$, se dispuso en el mismo sitio una zona de enterramientos cuyas fosas se practicaron horadando restos sedimentados de paredes de tapial -convertidos

colaboración de la arqueóloga A. B. Martínez García, de las empresas Unoveinte sL y Patrimonio Inteligente Castilla y León SL. En las diferentes campañas han participado alumnos de la Univ. de Valladolid que cursaban la asignatura de Prácticas del Grado de Historia. una vez depositado en el fondo de la sepultura el cadáver -con o sin caja-, se echó sobre él la misma tierra que previamente había sido retirada. Esto da lugar a que en el relleno de las Tumbas 1-3 y 8 se haya excavado un sedimento que tiene las mismas características que el nivel de época altoimperial en el que se practicaron las fosas y en el que aparecen fragmentos de TSH y de las producciones pintadas meseteńas y comunes. En los casos de las Tumbas 4-6, al excavar los rellenos intactos se identificaron -además de ese tipo de sedimento y de cerámicasvarios restos óseos menudos, algunas tachuelas, una cantonera y varios clavos de ataúdes descontextualizados -tanto de cabeza redonda como en 
forma de T- que por las profundidades a las que aparecieron y por su número no se pueden asociar en ningún caso a estos enterramientos ${ }^{4}$. Evidentemente esos elementos han de relacionarse con una zona cementerial que haya sido removida con anterioridad. En la amplia zona investigada entre 2013 y 2017 solo hay una necrópolis, esta tardía que analizamos; $\mathrm{y}$, puesto que las Tumbas 7, $9 \mathrm{y}$ 10 sí mostraban claros signos de expolio, hay que concluir que esos restos de sepulturas anteriores que identificamos en las Tumbas 4-6 deben proceder de ellas. Sin duda, es este un aspecto interesante ya que nos permite reconocer que, una vez saqueadas algunas sepulturas de especial entidad constructiva como la 9 y la 10, la necrópolis se siguió usando durante algún tiempo más, antes de abandonarse definitivamente. Todo ello hace posible una lectura en la que se reconocen tres momentos sucesivos en la configuración estratigráfica del cementerio: a) los primeros enterramientos -Tumbas 1-3 y 7-10-; b) un expolio materializado en la destrucción de varias sepulturas de la zona SE-Tumbas 7, 9 y 10- y en la realización de varias fosas de rebusca; c) una continuidad en los enterramientos -Tumbas 4-6-, posterior al robo hasta su definitivo abandono que viene señalado por una fosa inconclusa (Fig. 2).

Un hecho a destacar en este conjunto de enterramientos, del que sin embargo no pueden derivarse consideraciones de naturaleza cronoestratigráfica, es la singularidad de las Tumbas 9 y 10 , que presentan gruesos muros de mampostería caliza y, al menos de forma segura en la 9, mensa y una estructura aérea posiblemente abovedada. Otra, la Tumba 5, destaca por estar sellada con una plancha de mortero y algunos ladrillos macizos y por la gran anchura de la fosa, tal vez evidenciando el proyecto fallido de una estructura similar a la de las Tumbas 9 y 10 que no se pudo completar con piedra -y sí quizás con otro material de naturaleza perecedera- porque hubo que ocuparla antes de tiempo.

4 En la descripción de cada tumba, que se presenta en el apartado siguiente (Fig. 5), se hace referencia a esta cuestión.

\subsection{Los enterramientos}

A continuación se describen las diferentes tumbas según la numeración correlativa que se les fue asignando a lo largo de las diferentes campañas de excavación, independientemente de su ubicación en la necrópolis.

\subsubsection{Tumba 1: enterramiento femenino adulto} (Figs. 2 y 4-6)

La fosa tiene 2,25 m de longitud x 0,70 de anchura en la cabecera x 0,75 en los pies y $0,70 \mathrm{~m}$ de profundidad. El ataúd, calzado con piedras, se ha reconocido por los 18 clavos en forma de $\mathrm{T}$-de $9 / 10 \mathrm{~cm}$ de longitud de punta, medida que se repite en todas las tumbas- que fijaban las tablas. El esqueleto, en decúbito supino, presentaba los miembros inferiores en extensión y los brazos reposando, uno sobre el tórax y otro sobre el abdomen. Los restos óseos pertenecen a una mujer de 30/40 años de edad con una altura de $1,52 \mathrm{~m}( \pm 2 \mathrm{~cm})^{5}$. Dentro del ataúd, junto al pie derecho, estaba depositado el ajuar: un huso de hierro de $19 \mathrm{~cm}$ de longitud y sección circular y dos grandes astrágalos de cerdo; y como depósito ritual, un cuenco de cerámica de TSHT con perfil sinuoso, fechable desde finales del s. Iv hasta bien pasada la mitad del v y con un paralelo en la Tumba 7 de la necrópolis de La Morterona, en Saldaña (Abásolo et al., 1984: 40). Otras piezas similares a esta se han reconocido en los cementerios de La Olmeda, Palencia, y El Soto, en Barajas, Madrid (Vigil-Escalera, 2015: 201). El análisis de una muestra de sedimento adherido a la pared del recipiente (Aceituno y Lalinde, 2011: 252-255) ha revelado la presencia de almidones de cereales -trigo y avena-, que podrían relacionarse con el contenido del recipiente, bien en el momento de su

5 En los análisis de los individuos inhumados redactados por Pastor et al. [Pastor, J. F.; Barbosa, M.; De Paz, F. J.; Gutiérrez Reguera, B. y Montes, J. M.: Estudio antropológico y paleopatológico de los restos óseos humanos hallados en la intervención arqueológica del yacimiento de La Calzadilla (Almenara-Puras). Campaña de 2013. Informe inédito depositado en 2013 en la Junta de Castilla y León y en el 


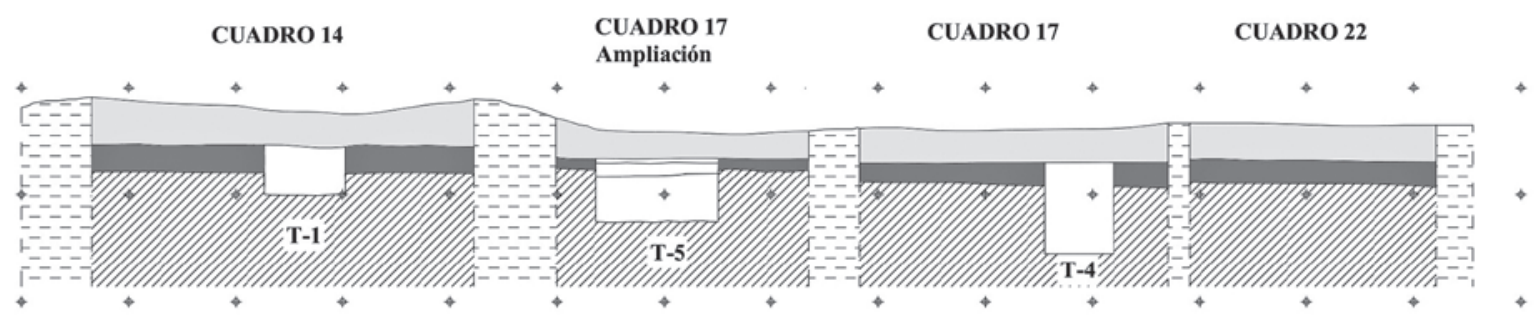

SECCIÓN 1 (NE - SO)

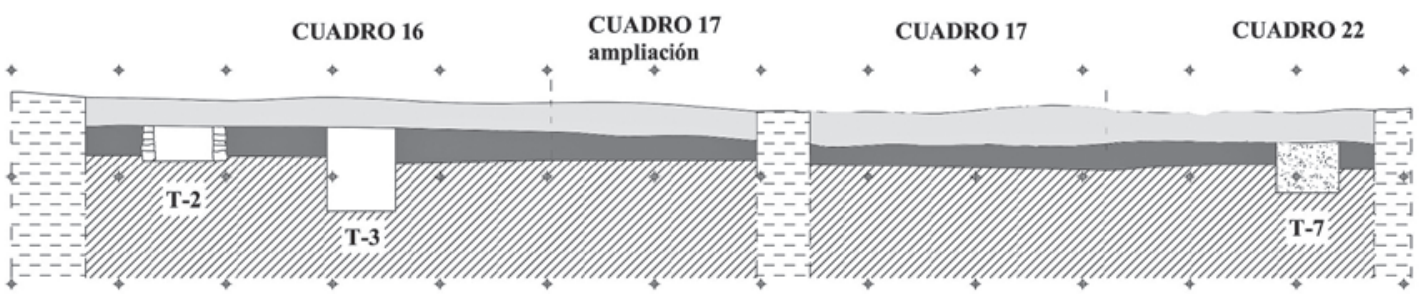

SECCIÓN 2 (NE - SO)

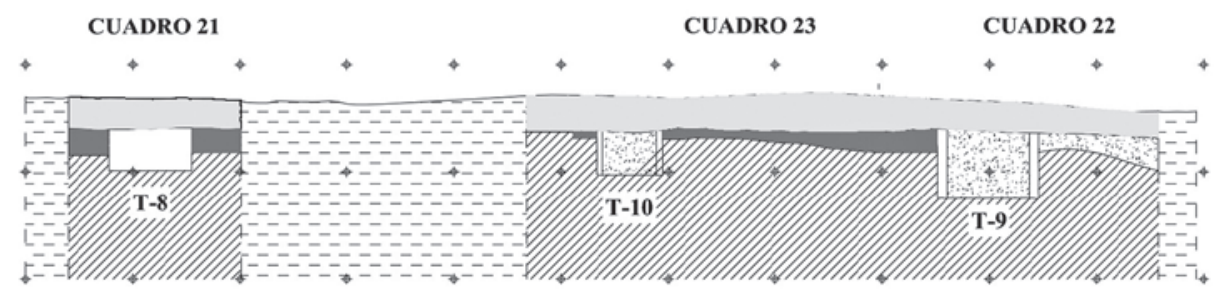

SECCIÓN 3 (NE - SO)
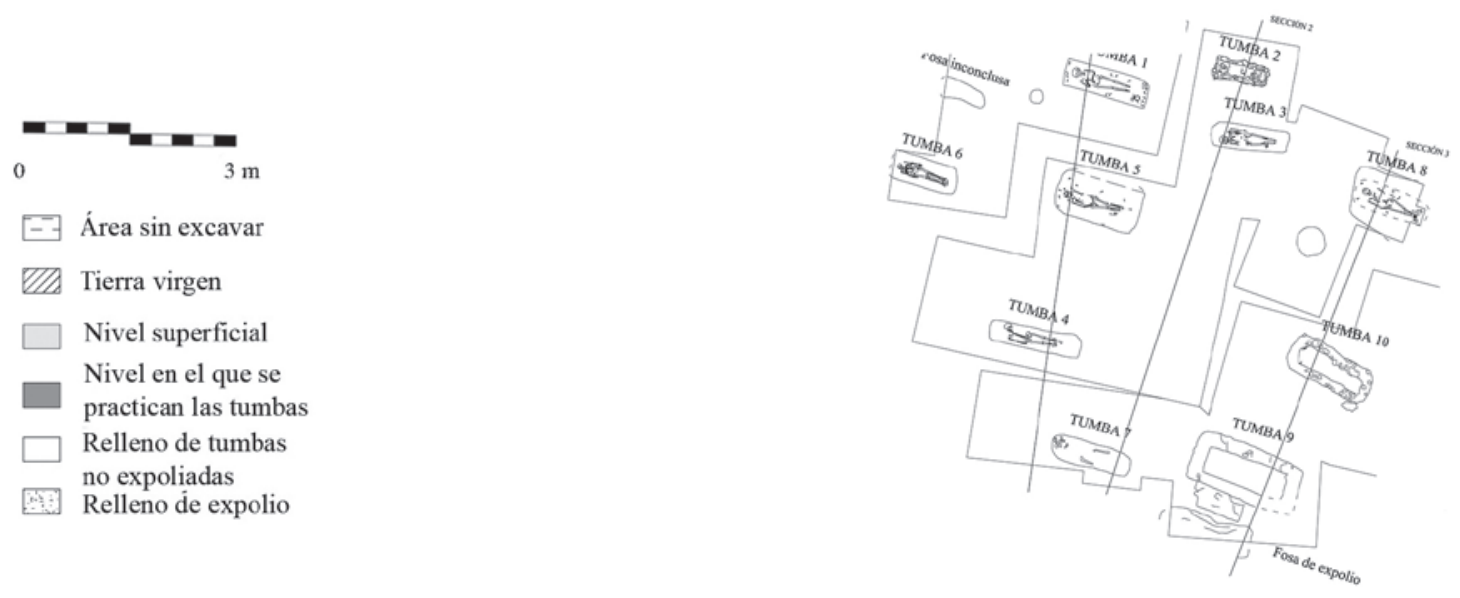

FIG. 3. Necrópolis postimperial de la villa de Almenara de Adaja-Puras: secciones. 
amortización en este enterramiento, bien con anterioridad a este uso funerario. Aunque no es posible asegurar, a la vista del análisis, si el cereal estuvo en estado sólido o líquido, podría haberse tratado de unas gachas, puesto que la forma del recipiente parece más apropiada para contener un alimento de consistencia líquida o semilíquida.

El huso, por su tamaño y por su peso de aproximadamente $40 \mathrm{~g}$, serviría para hilar lana o lino en la modalidad colgante, de la que hay numerosas representaciones en cerámica y relivaria antiguas. Los de hierro fueron muy frecuentes, al menos en las necrópolis rurales del mundo hispanorromano tardío, como evidencian, por citar algunas, la norte de la villa de La Olmeda en Palencia, la de Simancas y la de San Miguel del Arroyo en Valladolid (García-Merino y Sánchez-Simón, 2011: 244-246). Las grandes tabas, por su tamaño, no se adecúan al uso lúdico. El hecho de que una de ellas tenga un orificio donde encaja el huso nos lleva a plantear la posibilidad de que ambas compusieran un utensilio asociado a la pieza de hierro, cuya forma podría estar sugerida por la disposición en que se hallaron ambos astrágalos en el interior del ataúd: uno estaba en posición horizontal y el otro transversal al primero. Su funcionalidad concreta, en cambio, no es posible determinarla. Quizás este mismo tipo de instrumento, pero realizado en material perecedero como la madera, pudo haber formado parte del ajuar de otras tumbas con husos. La rueca, complemento necesario para el hilado, podría haber sido de madera, lo que explicaría su ausencia en el ajuar.

En lo que respecta a algunos aspectos paleopatológicos $^{6}$ se ha observado un callo en la segunda falange del primer dedo del pie izquierdo que indicaría una fractura antigua consolidada. Esta mujer

Museo de las Villas Romanas de Almenara-Puras)] se indica que para la estimación del sexo se tuvieron en cuenta la morfología craneal, la de la pelvis y la de los huesos largos; a partir de ello, se han podido reconocer hombres, mujeres e individuos alofisos o indeterminados. Para la estimación de la edad se han tenido en cuenta el grado de desgaste dentario y el estado general de osificación. Los rangos de edad se han establecido a partir de Campillo (2001).

6 Detallado en el correspondiente informe (Pastor et al., op. cit., n. 5).

Ediciones Universidad de Salamanca / 요요 había sufrido la pérdida de siete piezas dentarias ante mortem, mostraba una resorción alveolar de grado considerable y periodontitis, con desgaste afectando parcialmente a la dentina pero sin formación de cálculo. Además se observó una caries coronal en la pieza dentaria 13 y la 14 parecía hipoplásica y mostraba en su cara oclusal también una caries que afectaba a la pulpa. Y, por la detección de algunas líneas de Harris en determinados huesos, parece haber padecido fases de malnutrición o procesos infecciosos. Se han apreciado también como variación epigénetica dos huesos wormianos en la sutura parieto-occipital izquierda y un torus palatinum. En cuanto a los marcadores de estrés, hay que reseñar que sus dos fémures presentaban platimería con índices de 60,6 el derecho y 62,5 el izquierdo.

\subsubsection{Tumba 2: enterramiento infantil (Figs. 2, 4, 5, 7 y 8 )}

La fosa es rectangular con $1,20 \mathrm{~m}$ de longitud x 0,70 de anchura x 0,30 de profundidad; tiene las paredes reforzadas con una estructura de piedras calizas y cantos rodados, algunos de gran tamaño -de $30 \mathrm{~cm}$ de largo-. El cuerpo fue depositado en un ataúd calzado con dos grandes piedras, una en la cabecera y otra a los pies; la morfología de la caja se puede reconstruir por haberse conservados los 12 clavos en forma de $\mathrm{T}$ en su posición original: 6 en cada extremo corto. Quedaban muy escasos restos óseos y mal conservados: las extremidades inferiores, fragmentos craneales y gran número de piezas dentarias deciduas y permanentes aisladas que corresponden a un infantil de aproximadamente cinco años cuyo sexo no se ha podido concretar ${ }^{7}$.

No se halló ajuar a excepción de evidencias del calzado, colocado en la zona correspondiente a los pies, donde se han recogido 81 tachuelas de cabeza circular que miden, con la punta incluida, $1 \mathrm{~cm}$ de longitud. Ese elevado número de piezas de clavazón de las suelas es excesivo para una talla infantil, lo que parece apuntar a su valor simbólico en el rito funerario más que a su sentido como parte del ajuar.

Pastor et al., op. cit., n. 5. 
2.2.3. Tumba 3: enterramiento femenino adulto (Figs. 2, 4, 5, 9 y 10)

La fosa, rectangular con el lado de la cabecera curvo, mide $2,12 \mathrm{~m}$ x 0,80 de anchura $\times 0,80$ de profundidad. Albergaba un ataúd bien reconocible

\begin{tabular}{|c|c|c|c|c|c|c|}
\hline \multirow{2}{*}{$\begin{array}{c}\text { N. }{ }^{\circ} \text { Tumba } \\
1\end{array}$} & \multirow{2}{*}{$\begin{array}{l}\text { SEXo/EDAD } \\
\text { femenino/ } \\
\text { 30-40 años }\end{array}$} & \multicolumn{3}{|c|}{$\begin{array}{l}\text { DIMENSIONES DE LA FOSA EN CM } \\
\text { (ANCHURA/LONGITUD/PROFUNDIDAD) }\end{array}$} & \multirow{2}{*}{$\begin{array}{c}\text { TIPO DE FOSA } \\
\text { simple }\end{array}$} & \multirow{2}{*}{$\begin{array}{c}\text { Estado DE } \\
\text { LA Tumba } \\
\text { intacta }\end{array}$} \\
\hline & & 70 & 225 & 70 & & \\
\hline 2 & $\begin{array}{l}\text { infantil/ aprox. } \\
5 \text { años }\end{array}$ & $70 / 75$ & 120 & 30 & $\begin{array}{l}\text { con paredes } \\
\text { revestidas }\end{array}$ & intacta \\
\hline 3 & $\begin{array}{l}\text { femenino/ } \\
<25 \text { años }\end{array}$ & 80 & 212 & 80 & simple & intacta \\
\hline 4 & $\begin{array}{l}\text { femenino/ } \\
21 / 40 \text { años }\end{array}$ & 55 & 245 & 100 & simple & intacta \\
\hline 5 & $\begin{array}{l}\text { masculino/ } \\
19 / 20 \text { años }\end{array}$ & 176 & 228 & 60 & $\begin{array}{l}\text { con paredes } \\
\text { revestidas }\end{array}$ & intacta \\
\hline 6 & $\begin{array}{l}\text { femenino/ } \\
15 / 16 \text { años }\end{array}$ & 80 & 200 & 40 & simple & intacta \\
\hline 7 & $\begin{array}{l}\text { masculino/ } \\
21 / 40 \text { ańos) }\end{array}$ & 60 & 200 & 50 & simple & expoliada \\
\hline 8 & $\begin{array}{l}\text { alofiso/adulto } \\
21 / 40 \text { años }\end{array}$ & $70(?)$ & 200 (?) & 50 & simple & intacta \\
\hline 9 & $\begin{array}{c}\text { adulto } \\
21 / 40 \text { años }\end{array}$ & $\begin{array}{c}140 \\
\text { (70 en hueco } \\
\text { interno) }\end{array}$ & $\begin{array}{c}280 \\
\text { (210 en hueco } \\
\text { interno) }\end{array}$ & 60 & $\begin{array}{l}\text { con paredes } \\
\text { revestidas }\end{array}$ & expoliada \\
\hline 10 & sin datos & $\begin{array}{c}110 \\
\text { (70 en hueco } \\
\text { interno) }\end{array}$ & $\begin{array}{c}240 \\
\text { (200 en hueco } \\
\text { interno) }\end{array}$ & 40 & $\begin{array}{l}\text { con paredes } \\
\text { revestidas }\end{array}$ & expoliada \\
\hline
\end{tabular}

FIG. 4. Cuadro resumen de las características de las tumbas de la necrópolis postimperial de la villa de Almenara de Adaja-Puras.

por haberse mantenido 23 clavos en forma de $\mathrm{T}$ en su posición original. Algunos de ellos conservaban adheridos restos de madera cuyo análisis ha permitido saber que el material empleado para hacer la caja fue Pinus pinaster ${ }^{8}$.

En su interior había una mujer adulta, menor de 25 años, con una altura de $1,53 \mathrm{~m}- \pm 4 \mathrm{~cm}-$. Estaba en decúbito supino con la cabeza caída sobre el hombro derecho, los brazos extendidos a los lados del cuerpo y los tobillos juntos, posición que sugiere el amortajamiento. Carecía de ajuar personal, pero

8 Barrera, M.: Informe de quimica: Fragmentos ajuar funerario Almenara-Puras. Centro de Restauración de Bienes Culturales. Junta de Castilla y León. Informe inédito depositado en 2014 en la Junta de Castilla y León y en el Museo de las Villas Romanas de Almenara-Puras. como depósito del ritual funerario tenía, junto a la pierna derecha, un delicado cuenco de vidrio verdoso de la forma Isings 106, muy frecuente en el s. IV y con una larga historia de uso. Como ejemplos de necrópolis meseteńas en las que estos vasos acompañaban al difunto se pueden indicar las de La Olmeda

(Abásolo et al., 2004) y la de El Vergel en San Pedro del Arroyo (Moreda et al., 2011). A ello hay que añadir el calzado, del que se recuperaron 74 tachuelas, algunas de ellas todavía con fragmentos de cuero?.

La superficie ósea del esqueleto aparecía alterada por procesos de degradación tafonómica -en ningún caso por remociones en la tumba como bien se desprende de una estratigrafía que evidencia que el relleno original de la fosa estaba intacto-; esa es la causa de que no se identificaran fragmentos óseos de los pies y de que los elementos de las manos sean muy escasos. Y al hallarse por ese mismo motivo los huesos largos en muy mal estado, no fue posible utilizarlos para valorar la talla del individuo, cosa que se pudo estimar en unos $153 \mathrm{~cm} \pm 4 \mathrm{~cm}$ por medición directa del esqueleto in situ. Se identificó una artrosis leve en su rodilla derecha, pérdida ante mortem de una pieza dentaria y caries que afectaba ya a la dentina en otra pieza ${ }^{10}$.

\subsubsection{Tumba 4: enterramiento femenino adulto} (Figs. 2, 4, 5 y 11)

Esta fosa es la más honda de todas, tiene forma rectangular con los lados cortos redondeados,

9 Barrera, op. cit., n. 8.

10 Pastor et al., op. cit., n. 5. 


\begin{tabular}{|c|c|c|c|c|c|c|}
\hline \multirow{2}{*}{$\begin{array}{l}\text { N. }{ }^{\circ} \\
\text { TumbA }\end{array}$} & \multirow{2}{*}{ ATAÚd } & \multicolumn{2}{|c|}{ RESTOS METÁLICOS DEL ATAÚd } & \multirow{2}{*}{ AJUAR } & \multirow{2}{*}{ Depósito } & \multirow{2}{*}{$\begin{array}{c}\text { ReSTOS RELACIONADOS } \\
\text { CON EL EXPOLIO DE LAS TUMBAS 7,9 } \\
\text { y } 19\end{array}$} \\
\hline & & Clavos & Cantoneras & & & \\
\hline 1 & sí & $\begin{array}{c}18 \\
\text { en forma de } \mathrm{T}\end{array}$ & no & $\begin{array}{c}\text { huso y } \\
2 \text { astrágalos }\end{array}$ & $\begin{array}{l}\text { cuenco } \\
\text { de TSHT }\end{array}$ & no \\
\hline 2 & sí & $\begin{array}{c}12 \\
\text { en forma de } \mathrm{T}\end{array}$ & no & $\begin{array}{c}\text { calzado } \\
\text { (81 tachuelas) }\end{array}$ & no & no \\
\hline 3 & sí & $\begin{array}{c}23 \\
\text { en forma de } \mathrm{T}\end{array}$ & no & $\begin{array}{c}\text { calzado } \\
\text { (74 tachuelas) }\end{array}$ & $\begin{array}{c}\text { cuenco de vidrio } \\
\text { Ising } 106 \\
\end{array}$ & no \\
\hline 4 & no & no & no & pulsera y huso & no & $\begin{array}{l}\text { restos óseos menudos; } 2 \text { clavos } \\
\text { en forma de } \mathrm{T}, 1 \text { de cabeza } \\
\text { circular, } 5 \text { fragmentos de puntas } \\
\text { y } 1 \text { cantonera }\end{array}$ \\
\hline 5 & sí & $\begin{array}{l}16 \text { clavos de } \\
\text { cabeza circular }\end{array}$ & $\begin{array}{c}4 \text { cantoneras } \\
\text { rectangulares con clavos } \\
\text { de cabeza circular }\end{array}$ & $\begin{array}{c}\text { calzado } \\
\text { (84 tachuelas) }\end{array}$ & $\begin{array}{l}\text { bote de metal y pieza } \\
\text { indeterminada de hierro }\end{array}$ & $\begin{array}{c}\text { metatarsos humanos y } 3 \\
\text { tachuelas de calzado }\end{array}$ \\
\hline 6 & no & no & no & no & no & $\begin{array}{l}7 \text { clavos (6 de cabeza circular, } 4 \\
\text { en forma de } \mathrm{T} \text { y } 1 \text { fragmento de } \\
\text { otra punta) }\end{array}$ \\
\hline 7 & no & no & no & sin datos & sin datos & 3 clavos en forma de $\mathrm{T}$ \\
\hline 8 & sí & $\begin{array}{l}16 \text { clavos de } \\
\text { cabeza lateral }\end{array}$ & $\begin{array}{l}8 \text { cantoneras } \\
\text { rectangulares } \\
\text { con clavos de } \\
\text { cabeza circular }\end{array}$ & calzado & - & no \\
\hline 9 & $\begin{array}{l}\sin \\
\text { datos }\end{array}$ & sin datos & sin datos & sin datos & sin datos & - \\
\hline 10 & sí & $\begin{array}{c}5 \text { clavos de } \\
\text { cabeza circular }\end{array}$ & sin datos & sin datos & sin datos & - \\
\hline
\end{tabular}

Fig. 5. Otras características de las tumbas de la necrópolis postimperial de la villa de Almenara de Adaja-Puras.

de $2,45 \times 0,55 \times 1 \mathrm{~m}$ de profundidad. Contenía una mujer adulta de $1,51 \mathrm{~m}- \pm 2 \mathrm{~cm}-$ de altura en decúbito supino con la cabeza ladeada hacia el hombro izquierdo y los tobillos juntos, posible indicio de amortajamiento. El ajuar, depositado junto al pie derecho, constaba de una pulsera de bronce y un huso de hierro. La pulsera es acintada con un sencillo broche y decorada con dos hileras horizontales de un pequeño motivo circular radiado, repetido en secuencia.

No hay indicios de ataúd claveteado. En efecto, aunque entre la tierra echada sobre el cuerpo se recuperaron a distintas profundidades algunos elementos relacionables con una caja -2 clavos completos con cabeza en forma de $\mathrm{T}$, otro de cabeza circular, 5 fragmentos de la punta de otros y una cantonera casi completa-, dada además su localización en el relleno, resultan a todas luces muy escasos para defender la presencia de un ataúd. Más bien todo parece apuntar a que son restos relacionados con el expolio a que fueron sometidas las vecinas Tumbas
9 y 10. Lo mismo cabe decir de la presencia, a una profundidad de unos $60 \mathrm{~cm}$-en el relleno- de una bolsada de cascotes - piedras calizas y fragmentos de ladrillos- y el fondo casi completo de un recipiente de cerámica común.

En lo que se refiere a la paleopatología odontológica se constató en esta mujer adulta resorción alveolar de grado ligero y la presencia de un absceso que en su momento drenó al exterior en el alveolo de la pieza dentaria 2. Como paleopatología craneal cabe destacar la presencia de exóstosis en el hueso cigomático derecho, secundaria probablemente a fractura tras un traumatismo en esta región malar. Además mostraba una artrosis generalizada, constatable en los restos vertebrales y articulaciones sacroilíacas, así como una asimetría en los cuerpos de tres vértebras torácicas medias, con disminución en la altura de la mitad izquierda de los mismos y la desviación consecuente de los arcos vertebrales correspondientes. También en su esqueleto se ha apreciado la presencia de unas carillas lisas, similares a 

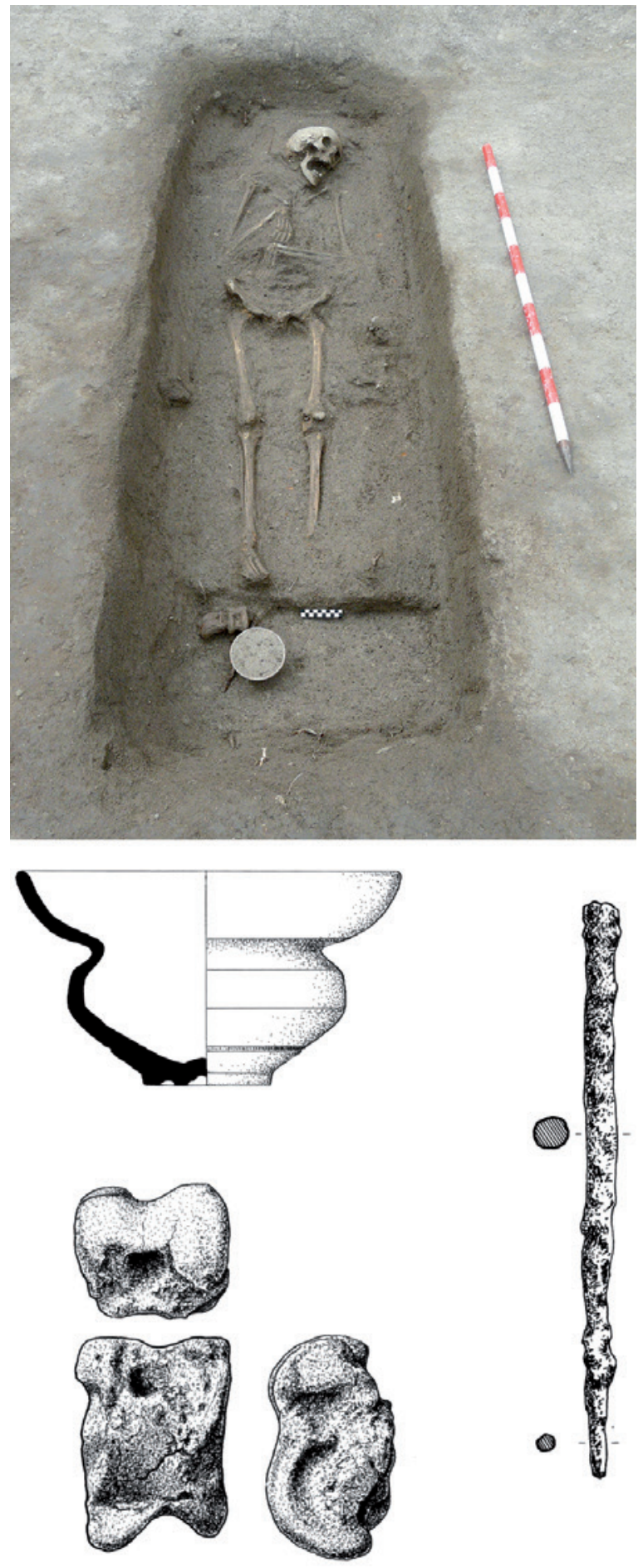

FIG. 6. Tumba 1: arriba, vista general con restos óseos y abajo, depósito funerario (dibujos de A. Rodríguez).

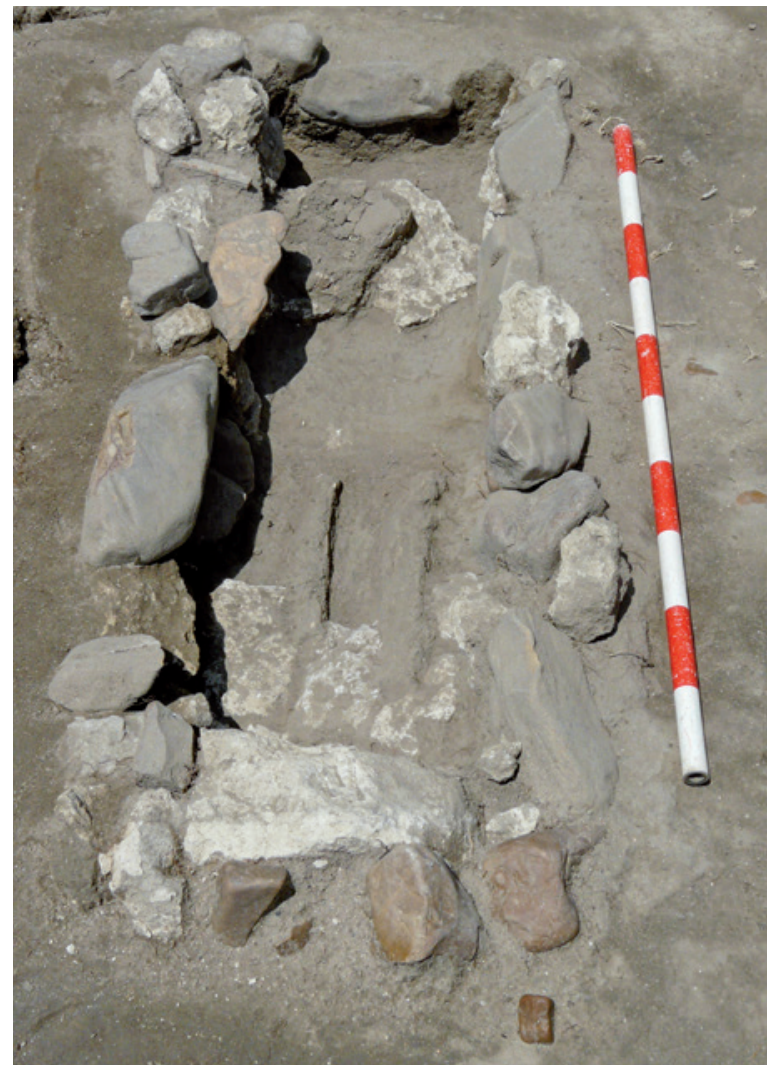

FIG. 7. Tumba 2: vista general con restos óseos.

facetas articulares, en la tuberosidad isquiática de ambos coxales y un borde interóseo del cúbito derecho y una inserción del músculo pronador cuadrado muy marcado, lo que estaría relacionado con la realización de movimientos de pronación continuados y de alta intensidad. Otro rasgo es que la mujer inhumada en esta tumba presentaba un agujero condíleo anterior derecho doble y un agujero supernumerario en la raíz posterior de la apófisis transversal derecha de una vértebra cervical ${ }^{11}$.

\subsubsection{Tumba 5: enterramiento juvenil masculino (Figs. 2, 4, 5 y 12-14)}

Esta tumba destaca del resto por las amplias dimensiones de la fosa-de 2,28 m de longitud x 1,76 de anchura conocida $\mathrm{x}$ 0,60 $\mathrm{m}$ de profundidad-. El

11 Pastor et al., op. cit., n. 5. 
ataúd también era grande $-1,80$ x $0,80 \mathrm{~m}-\mathrm{y}$ se situaba en el centro; de él se han recuperado las 4 cantoneras rectangulares de hierro -placas de aproximadamente $2,5 \mathrm{~cm}$ de anchura $\mathrm{x} 15$ de longitud, dobladas hacia la mitad, que se ajustan en la madera con un par de puntas de cabeza redonda- y los 16 clavos -también de hierro y de cabeza circular- en su posición original, lo que ha permitido conocer no solo las dimensiones de la caja, sino también que estaba hecha con tablas de $2,5 \mathrm{~cm}$ de grosor. Piezas como estas descritas tienen claros paralelos en las necrópolis del yacimiento palentino de La Morterona, en Salda-

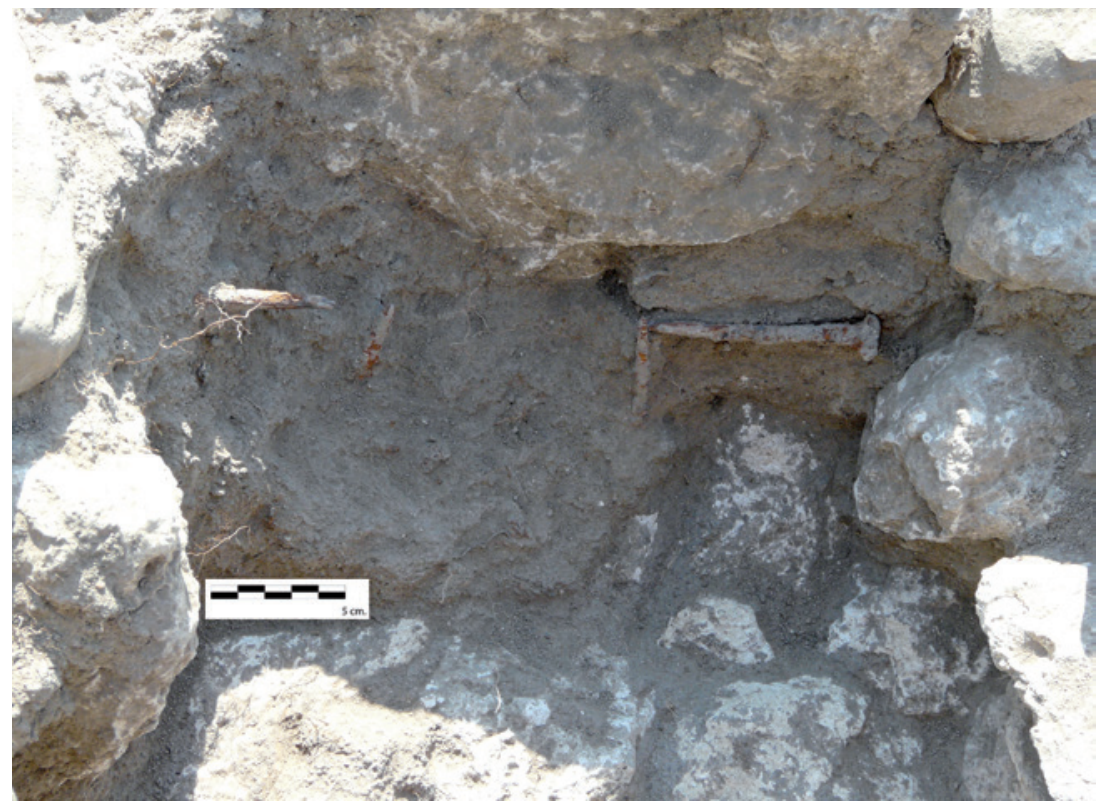

Fig. 8. Tumba 2: detalle de los clavos del ataúd en la zona de los pies. ña (Abásolo et al., 1984: 74, 75 y 77) y del abulense de El Vergel, en San Pedro del Arroyo (Moreda et al., 2011).

Como singularidad respecto a otras tumbas, se dispuso cubriéndola una gruesa plancha de mortero sobre cama de cantos rodados. Esta cubierta no enrasa con la cota de uso de las calles de la necrópolis, sino que está unos 10/15 cm más honda, rellenándose el resto de la fosa con escombros entre los que había dos baldosas latericias enteras y fragmentos de otras. En la necrópolis madrileńa de Gózquez de Arriba, en San Martín de la Vega, también se hallaron cierres, en este caso lajas pétreas, por debajo de la superficie de frecuentación original (Vigil-Escalera, 2013: 282). En Almenara, la presencia de esa plancha de mortero exclusivamente sobre el ataúd que ocupa una posición centrada en la tumba parece señalar que el espacio interno de la fosa -el útil para depositar la caja- es menor que la anchura total del corte. Y, pese a que no se han recuperado evidencias de una posible estructura perimetral -como sí en cambio ocurre en las Tumbas 9 y 10, aunque en estos dos casos con muros pétreos-, se podría considerar como posibilidad que hubiese existido, pero realizada en material perecedero.
El ataúd contenía los restos de un varón de 19/20 años de edad, de $1,73 \mathrm{~m}- \pm 2 \mathrm{~cm}-$ de estatura, en decúbito supino. El brazo derecho estaba flexionado ligeramente y la mano entre los muslos mientras que el brazo izquierdo quedaba extendido, las piernas estiradas y los tobillos juntos. Las numerosas tachuelas del calzado -84, algunas incluso con restos de cuero- que se encontraban junto al pie izquierdo indican que el inhumado estaba descalzo, como corresponde al amortajamiento, presumible por la posición de los tobillos.

El depósito funerario colocado junto a la pierna derecha consiste en un bote cilíndrico de bronce de paredes verticales y con tapa convexa de igual metal $y$ un instrumento de hierro afectado por la oxidación (Fig. 14). El recipiente, de $6 \mathrm{~cm}$ de altura $\mathrm{x} 3$ de diámetro, está realizado con una fina lámina de bronce con baño exterior de estaño ${ }^{12}$ y los extremos

12 Martín Mateo, R.: NGR 454. Caja ajuar funerario La Calzadilla. Almenara-Puras VA Centro de Restauración de Bienes Culturales. Junta de Castilla y León. Informe inédito depositado en 2014 en la Junta de Castilla y León y en el Museo de las Villas Romanas de Almenara-Puras. El bote no pudo abrirse debido a su frágil estado de conservación; de ahí que no se haya podido realizar ningún otro análisis. 
soldados formando un cilindro, unido a otra lámina circular con perfil levemente umbilicado que le sirve de fondo. Las uniones están realizadas de un
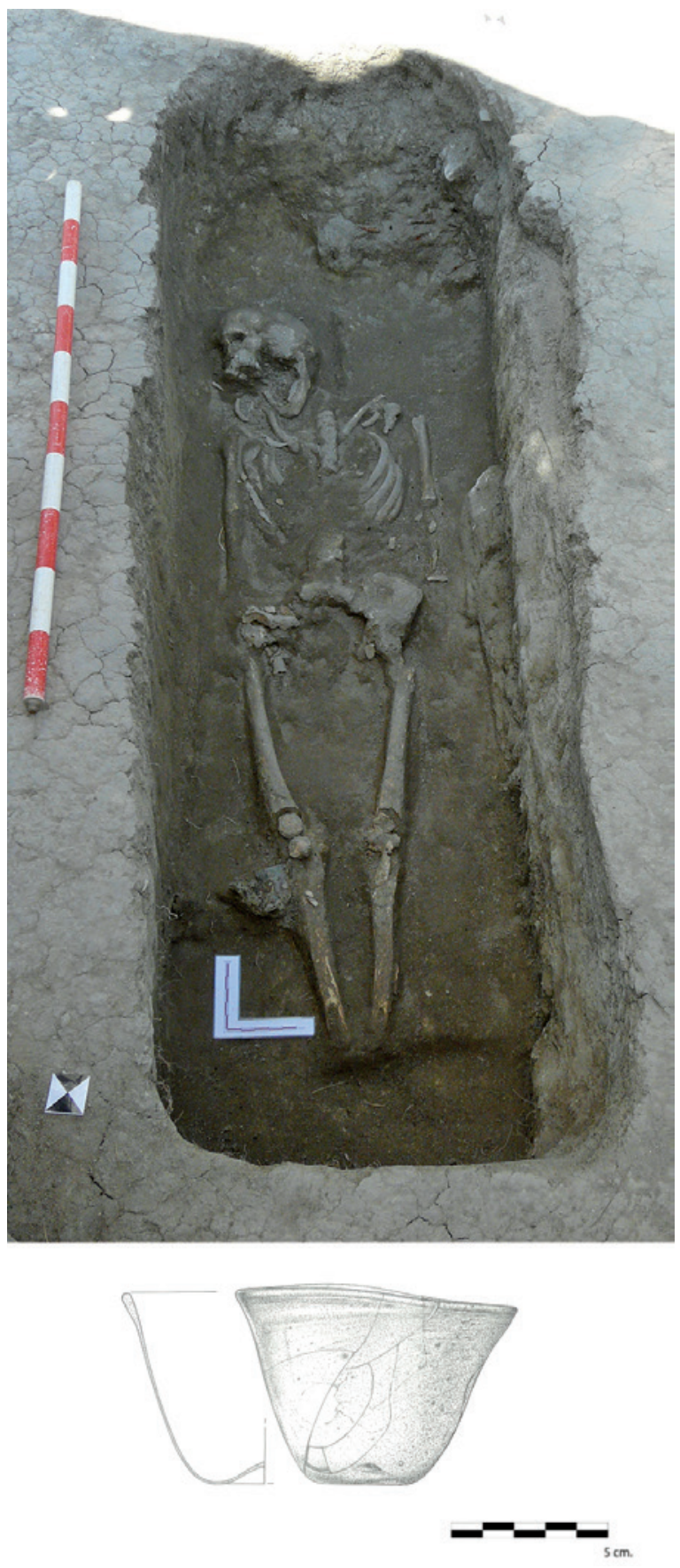

Fig. 9. Tumba 3: arriba, vista general con restos óseos; abajo, depósito funerario (dibujo de A. Rodríguez).

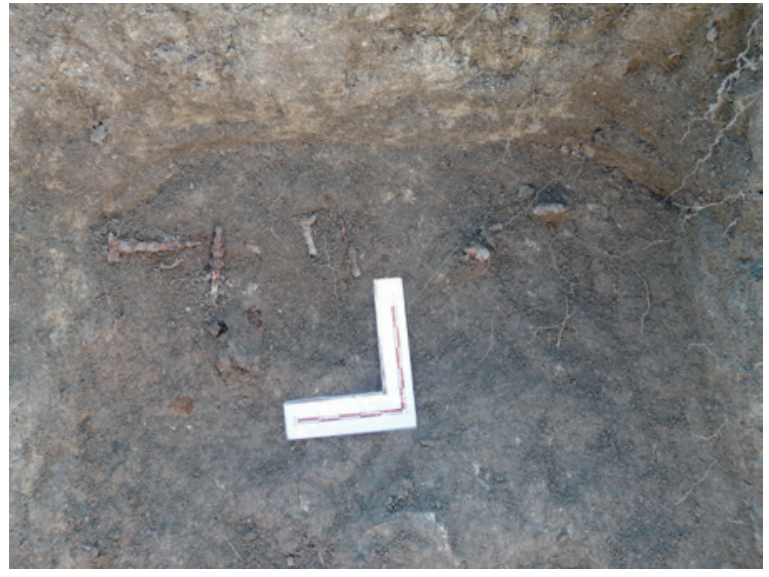

FIG. 10. Tumba 3: detalle de los clavos del ataúd en la zona de los pies.

modo inusual mediante pestańas. Muestra una ligera ornamentación con tres parejas de líneas incisas alrededor del cuerpo, una en la base, otra a media altura y otra bajo la boca. La tapa convexa, con depresión central, presenta un orificio de $4 \mathrm{~mm}$ de diámetro en el centro, posiblemente para insertar un pomo de materia orgánica. El análisis realizado de una muestra de la tierra que contenía ha revelado la presencia de microcarbones de fitolitos de cereales además de diversos microrresiduos indeterminados ${ }^{13}$. Su capacidad es un cyathus, es decir, 45 $\mathrm{ml}$ (Alonso et al., 2019: 258). En cuanto al objeto de hierro, de $15 \mathrm{~cm}$ de longitud y perfil ligeramente curvo, es de sección rectangular, de $1 \mathrm{~cm}$ de anchura y de 3 o $4 \mathrm{~mm}$ de espesor. Uno de los extremos se estrecha, apuntándose; el contrario, en cambio, se ensancha hasta los $2 \mathrm{~cm}$ y remata en un bisel. Desconocemos su funcionalidad, si bien la forma podría sugerir un doble uso: espátula y perforador/ rascador, o un incómodo estilete para escribir sobre tablilla de cera.

Se han hallado recipientes cilíndricos parecidos en tumbas de cronología tardía de entornos rurales. En el cementerio de Albalate de las Nogueras

13 Aceituno, F. J.: Informe: análisis de micro residuos vegetales. Museo de las Villas Romanas de Almenara-Puras. Universidad de Antioquía (Colombia). Informe inédito depositado en 2014 en la Junta de Castilla y León y en el Museo de las Villas Romanas de Almenara-Puras. 


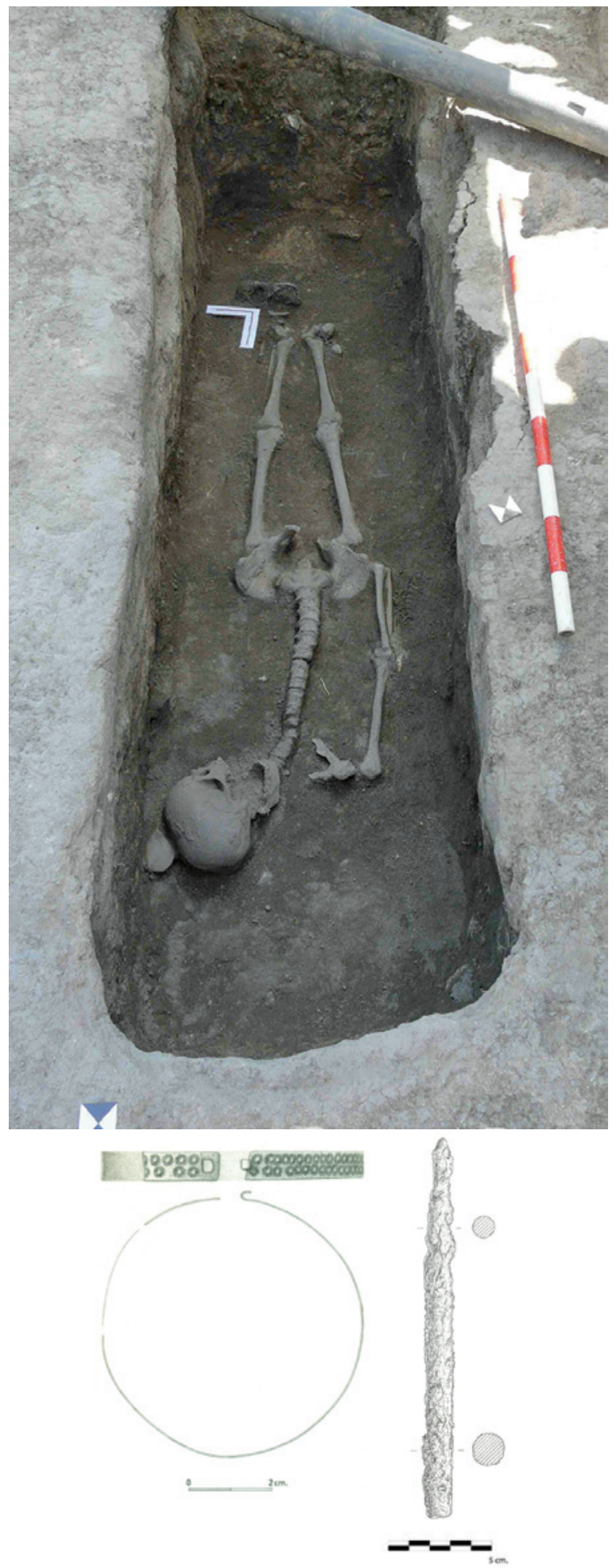

FIG. 11. Tumba 4: arriba, vista general con restos óseos; abajo, depósito funerario (dibujos A. Rodríguez).
(Cuenca) se documentaron tanto en la Tumba 1 como en la 3 (Fuentes, 1989: 29-35). Interpretado como "pomo de botica" -narthecium o cotulla- en el primer caso, hay un ejemplar incompleto realizado con una lámina de bronce de $5 \mathrm{~cm}$ de altura $\mathrm{x}$ 3 de diámetro, que no conserva la tapa; ofrece decoración a base de líneas incisas paralelas alrededor de la pared. Con él se depositaron también un jarro de cerámica común, dos hachas y dos instrumentos de hierro; uno está formado por una placa rectangular de 6,2 cm de longitud x 2,1 de anchura

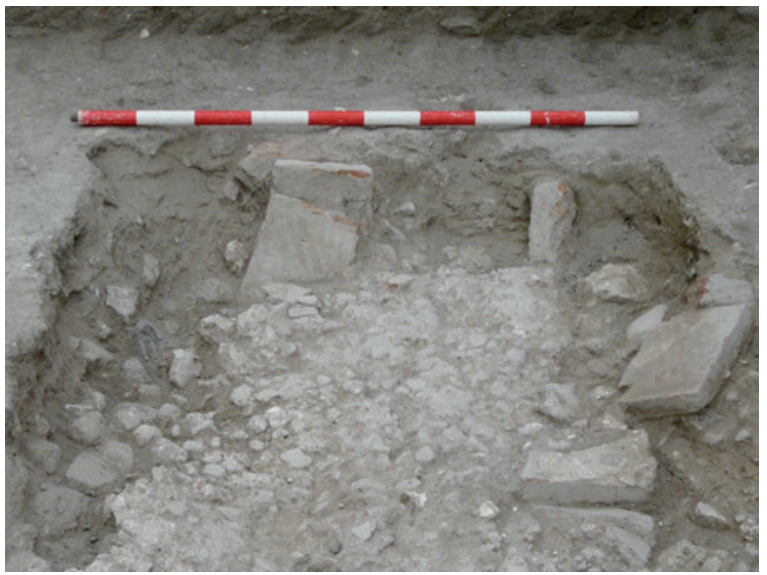

Fig. 12. Tumba 5: detalle de la cubierta en la zona de la cabecera.

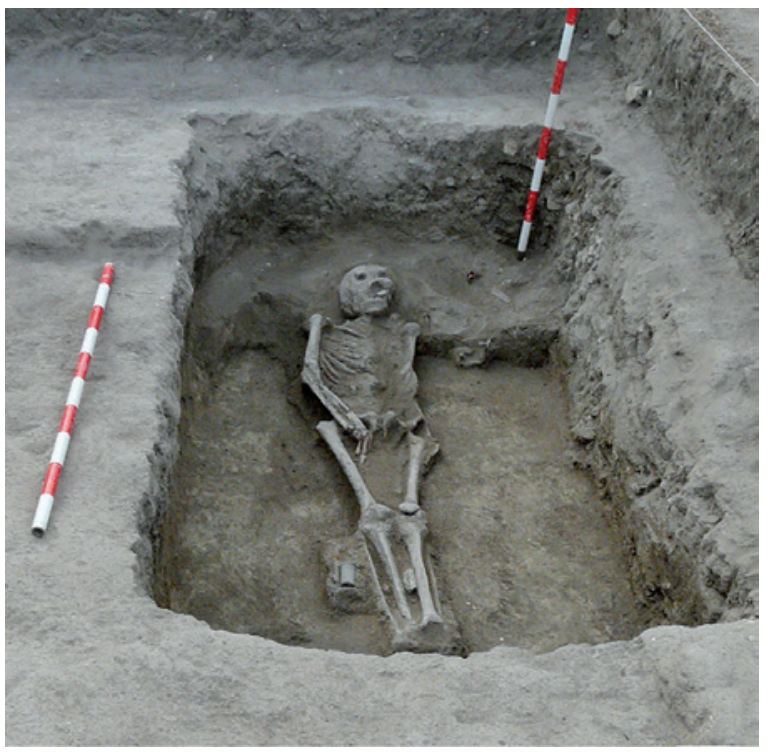

FIG. 13. Tumba 5: vista general con restos óseos y depósito. 
cuyo espesor es de $2 / 4 \mathrm{~mm}$; uno de sus extremos es ligeramente más ancho y remata en bisel; el otro objeto, de casi $15 \mathrm{~cm}$ de longitud, es piriforme y un extremo posiblemente preparado para engarzar otra pieza. De la Tumba 3 se recuperaron, además de un anillo de plata, otros dos pomos cilíndricos hechos con láminas de bronce, ninguno de los cuales conserva la tapa; uno es más alto -de $14 \mathrm{~m}-\mathrm{y}$
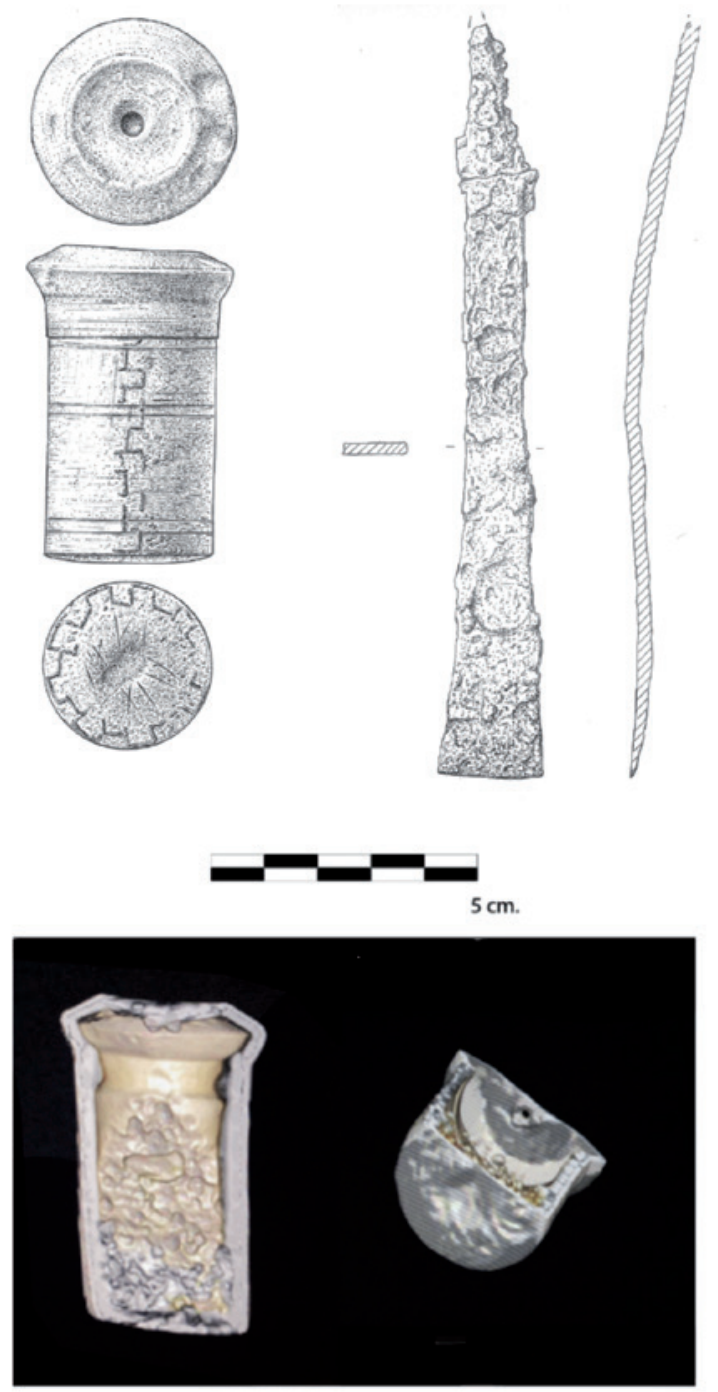

Fig. 14. Depósito funerario de la Tumba 5: arriba, bote metálico y útil de hierro (dibujos de A. Rodríguez); abajo, radiografia del bote; las secciones muestran su morfología y el interior con sedimento (fotografias de J. F. Pastor). estrecho $-<3 \mathrm{~cm}$ de diámetro-; el otro es más bajo $-4,5 \mathrm{~cm}-$ y prácticamente de igual anchura. Además, en la necrópolis de Roda de Eresma, Segovia, en la Tumba 23, se identificó otro pequeño bote cilíndrico de bronce acompañado de un recipiente de vidrio indeterminado, una jarra de cerámica común y un utensilio de hierro del que no se detalla nada más (Fuentes, 1990: 176).

Respecto a la posible función de este tipo de objetos, de la información al respecto derivada de las necrópolis de Valladolid y de Cuenca no se infiere con seguridad ni su uso concreto, ni su asociación recurrente con algún otro objeto realizado en material no perecedero, aunque sí podría haberse dado con otros que hayan podido pudrirse. No obstante, sí queremos indicar que el utensilio de hierro terminado en bisel de la Tumba 1 de Albalate podría asemejarse al de Almenara si aquel hubiera estado enmangado en otro, formando parte de una posible espátula. Los tres pomos citados comparten una misma factura a partir de delgadas láminas metálicas; las dimensiones - altura y anchura- responderán probablemente a usos distintos; así, aquel más largo podría haber sido una caja para guardar instrumental quirúrgico o un estuche o theca para cálamos o para estiletes (Alonso et al., 2014: 175). En cuanto a los más pequeños, con tamaños que rondan los $4 / 5 \mathrm{~cm}$ de alto, al no conservarse las tapas, bien podrían ser pyxides, bien tinteros, si tenemos presentes los problemas de identificación de los atramentaria que señalan J. Alonso et al. (2014: 178). En relación con esto último es sugerente la asociación en la Tumba 3 de Albalate de las Nogueras, mencionada más arriba, de dos botes de similar diámetro y diferente tamaño que podrían formar parte de un mismo juego relacionado con la escritura de los que se conocen algunos ejemplos (Eckardt, 2018: 38-39). De todos esos recipientes el más completo es el de Almenara, siendo el único que se conserva íntegro, incluida su tapa convexa. Gracias a la radiografía que mostramos en la Fig. 14 sabemos que las paredes son rectas y que carece en el borde de un disco o anillo con una abertura para mojar el cálamo (y escurrir la tinta sobrante), pieza fundamental en un tintero. En cambio, el único orificio de la tapa 


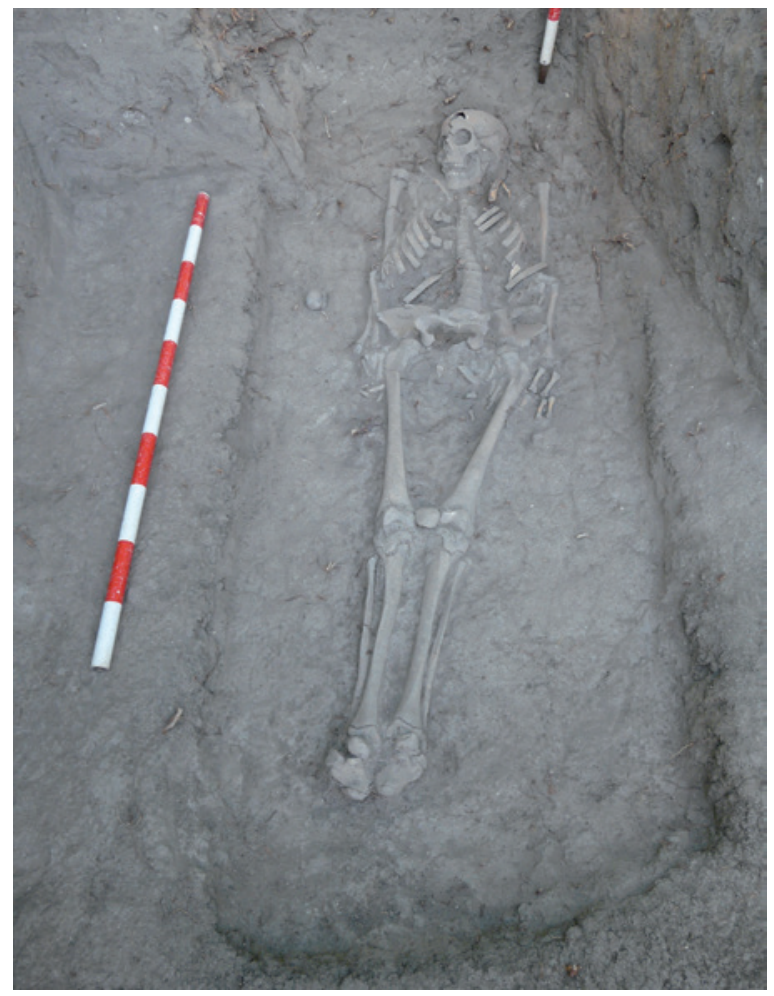

FIG. 15. Tumba 6: vista general con restos óseos.

es muy pequeño $(3 / 4 \mathrm{~mm})$, sin duda más propio para engarzar un tirador ${ }^{14}$. A pesar de la carencia de ese anillo, piezas similares halladas en tumbas de Krefeld-Gellep (Alemania), Keszthely-Úsztató (Hungría) y Rusovce-Orcszvár (Eslovaquia) y datadas a finales del s. III y avanzado el IV se adscriben a tinteros del tipo inkwells with removable lid but no surviving chain, según la tipología de $\mathrm{H}$. Eckardt (2018: 91 y fig. 5.14b).

Los restos óseos de este individuo juvenil estaban bien conservados. Se pudo apreciar con radiografías convencionales la presencia de líneas de Harris en los huesos de las extremidades inferiores que indicarían periodos de crecimiento interrumpidos. También se constató la formación de cálculos de grado ligero en los incisivos superiores y que la pieza dentaria 48 no había erupcionado y aparecía

14 H. Eckardt (2018: 91) asocia en este tipo el pequeño orificio central para el enganche de una cadena, cadena que en ninguno de los ejemplos conocidos parece haberse documentado. Eso mismo ocurre en el caso de Almenara.

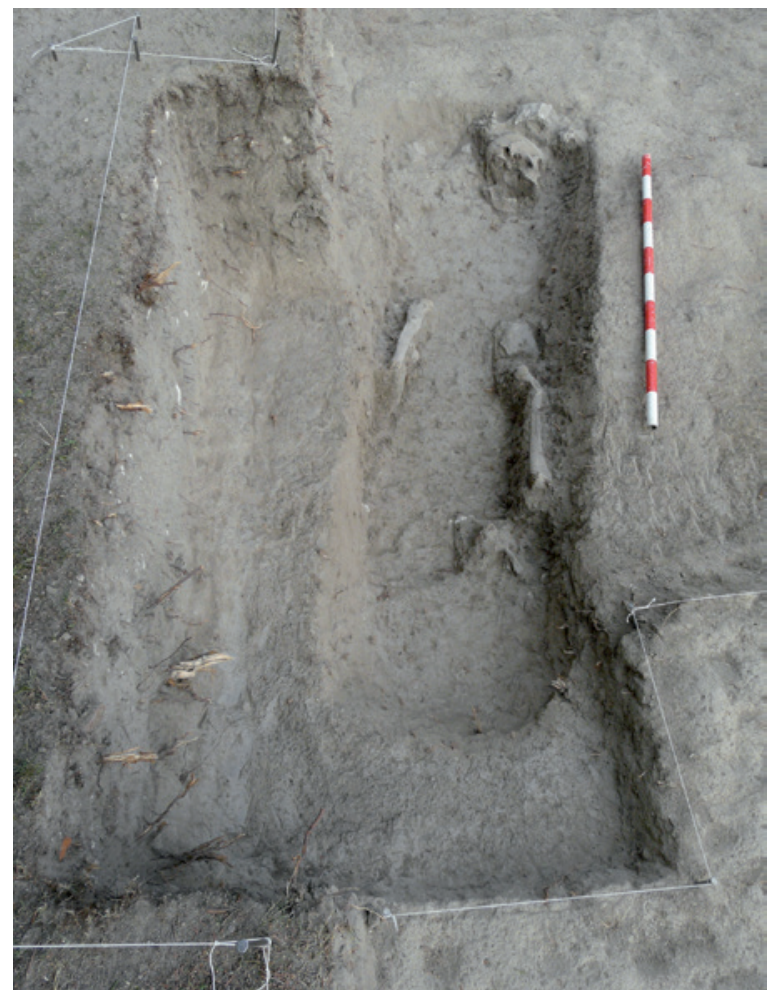

FIG. 16. Tumba 7: vista general con restos óseos.

impactada contra la cara distal del 47, al tratarse de un tercer molar retenido en posición horizontal. También se ha identificado una sutura metópica ${ }^{15}$.

Una cuestión reseñable es que en el relleno de esta sepultura se han hallado 5 metatarsos y 3 tachuelas junto al borde norte de la fosa, pero claramente al exterior del ataúd. Por su localización no pueden relacionarse con el individuo inhumado, pero podrían pertenecer a alguno de los cadáveres de las tumbas expoliadas.

\subsubsection{Tumba 6: enterramiento juvenil femenino} (Figs. 2, 4, 5 y 15)

La fosa es rectangular, tiene $2 \mathrm{~m}$ de longitud $\mathrm{x}$ 0,80 de anchura y 0,40 de profundidad. En ella se depositó el cuerpo -posiblemente amortajado a tenor de la posición de los tobillos- de una mujer de edad juvenil, de 15/16 años, sin ajuar ni calzado y

15 Pastor et al., op. cit., n. 5. 


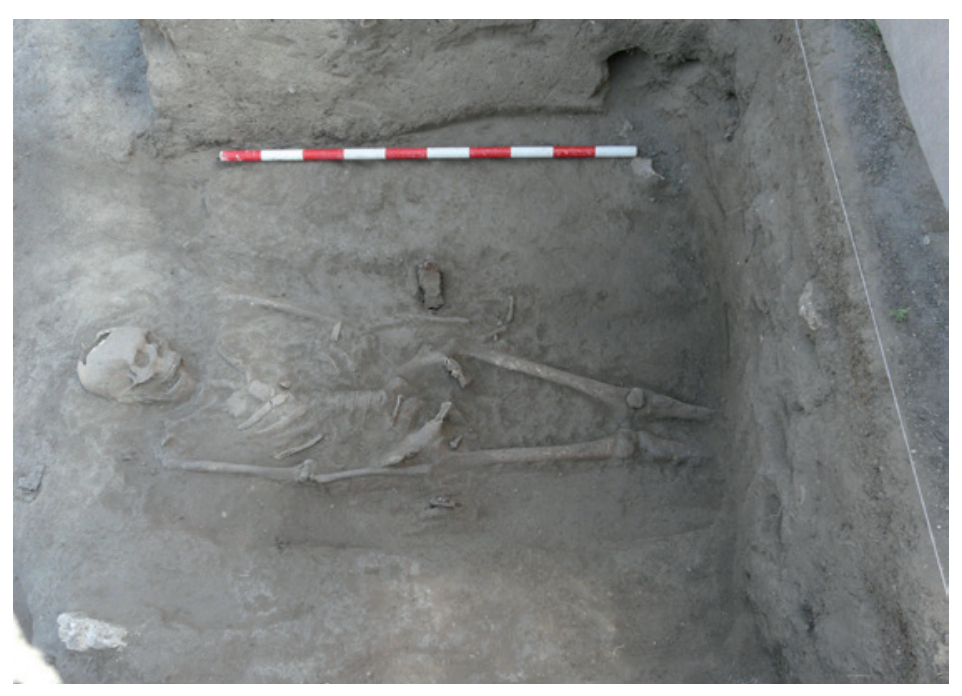

FIG. 17. Tumba 8: vista general con restos óseos en proceso de excavación.

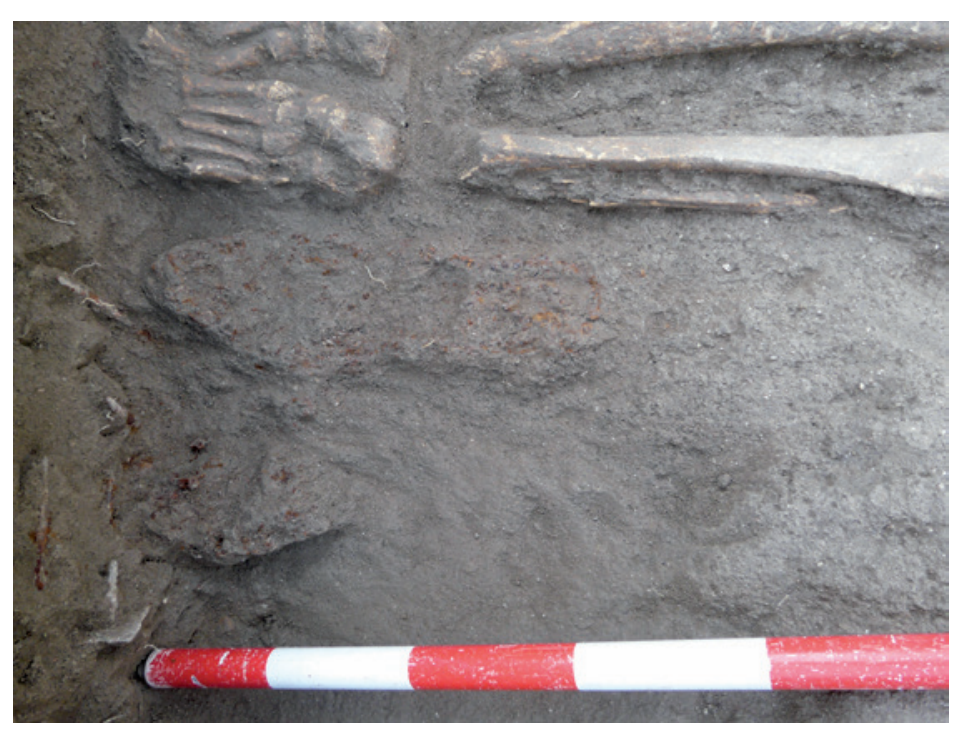

FIG. 18. Tumba 8: detalle del calzado depositado a los pies.

Los restos óseos estaban bien conservados. Cabe señalar la presencia de un hueso wormiano en la sutura lamboidea y que en los aspectos odontológicos, junto a una escasa resorción alveolar en la mayoría de las piezas, se observó un absceso apical en el alveolo de la pieza dentaria 35 secundario a un proceso infeccioso ${ }^{16}$.

\subsubsection{Tumba 7: enterramiento masculino adulto (Figs. 2, 4, 5 y 16)}

La fosa, de $2 \mathrm{~m}$ de largo x 0, 60 de ancho x 0,50 de profundidad, es rectangular con cabecera curva y extremo opuesto plano. Esta tumba fue expoliada en época tardoantigua. La acción de rebusca afectó especialmente a la zona del tronco y de las extremidades del esqueleto: la mayor parte de los huesos fueron destrozados o desplazados de su posición original; solo la cabeza quedó intacta. No hay indicios claros de ataúd porque, aunque la tumba estaba expoliada, esa acción no afectó a la cabecera donde el cráneo estaba relativamente bien conservado y no había clavos. Los 3 clavos en forma de $\mathrm{T}$ documentados no estaban in situ, sino en el relleno y a distintas profundidades.

Los restos esqueléticos residuales -el cráneo casi completo y elementos del cinturón cleidoescapular- corresponden a un varón adulto menor de 40 años, de $1,60- \pm 2 \mathrm{~cm}-$ de altura. Se aprecia una lesión osteolítica deprimida e irregular en el parietal izquierdo y un callo de frac-

cuya talla no pudo estimarse por estar aún la mayoría de las epífisis sin fusionar. No hay evidencias de ataúd claveteado, aunque entre la tierra con la que se colmató la fosa se han encontrado a diferentes profundidades 7 clavos -6 de cabeza circular, 4 en forma de $\mathrm{T}$ y un trozo más de otra punta-. Por la ubicación de cada uno de ellos no es posible relacionarlos con la clavazón de la caja y sí con restos de las tumbas que fueron expoliadas previamente. tura acompañado de osteomielitis en la tibia izquierda. Además, se constató un desgaste dental

16 Pastor, J. F.; Barbosa, M.; De Paz, F. J.; Gutiérrez Reguera, B. y Montes, J. M.: Estudio antropológico y paleopatologico de los restos óseos humanos hallados en la intervención arqueológica del yacimiento de La Calzadilla (Almenara-Puras). Campaña de 2015. Informe inédito depositado en 2015 en la Junta de Castilla y León y en el Museo de las Villas Romanas de Almenara-Puras. 
considerable, la pérdida de dos piezas dentarias ante mortem, resorción alveolar con presencia de periodontitis en otras y una caries que afectaba ya a la dentina en el segundo molar superior derecho ${ }^{17}$.

\subsubsection{Tumba 8: enterramiento de individuo adulto alofiso (Figs. 2, 4, 5, 17 y 18)}

La fosa tiene $2 \mathrm{~m}$ de longitud, una anchura mínima ${ }^{18}$ de 0,70 × 0,50 de profundidad. El ataúd debía medir aproximadamente $1,70 \times 0,70 \mathrm{~m}$, referencia que se estima gracias a haberse identificado los elementos de trabazón: 16 clavos -de 8,5 cm de largo- de ca-

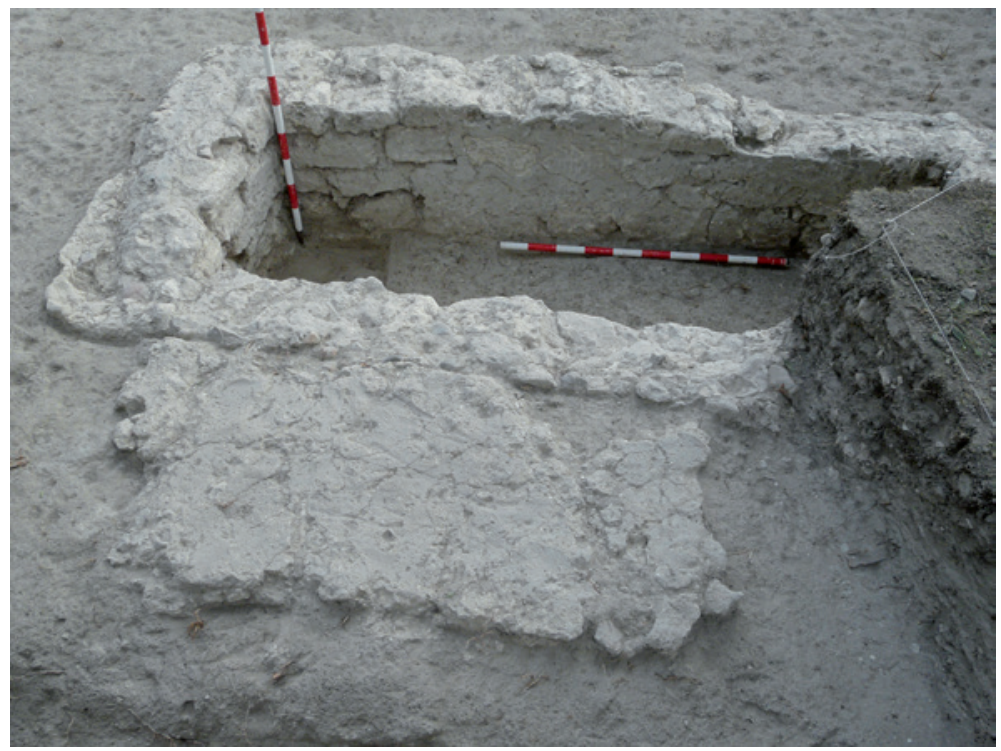

FIG. 19. Tumba 9: vista general.

Poirier. En el cráneo se aprecian un torus palatinum y todas las piezas dentarias, presentando únicamente una ligera resorción alveolar y un desgaste muy marcado de la superficie oclusal ${ }^{19}$.

\subsubsection{Tumba 9: enterramiento de individuo adulto indeterminado (Figs. 2, 4, 5 y 19)}

Las dimensiones exteriores de la tumba son 2,80 $\mathrm{m}$ de longitud, $1,40 \mathrm{~m}$ de anchura y $0,60 \mathrm{~m}$ de profundidad; las internas de $2,10 \times 0,70 \mathrm{~m}$. La fosa está revestida con un muro -de 0,40 m de espesor- fabricado con mampuestos calizos de mediano tamaño -aproximadamente de $20 / 30 \mathrm{~cm}$ de largo $\mathrm{x}$ 10 de alto- toscamente desbastados y trabados con abundante mortero de cal y arena. Se conservan tres hiladas de su altura original, parámetro que no podemos determinar. No quedaban restos ni del ataúd ni del ajuar, tampoco del depósito funerario, pero sí algunos del esqueleto que corresponden a un adulto cuyo sexo no se pudo determinar por carecer de elementos suficientes: rótula derecha, tibia izquierda, fragmentos de ambos calcáneos, astrágalo izquierdo

19 Pastor et al., op. cit., n. 16. 


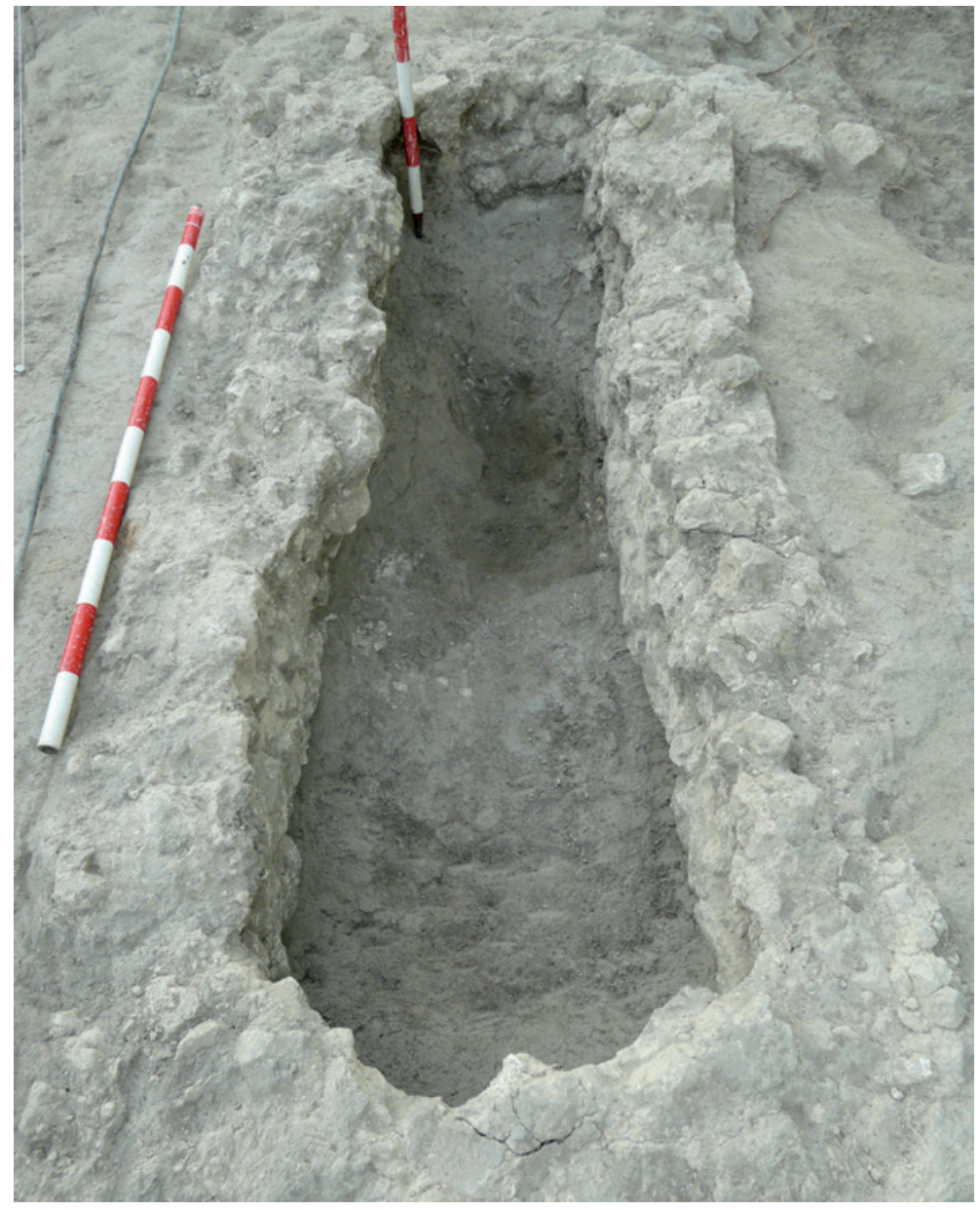

FIG. 20. Tumba 10: vista general.

incompleto, tres fragmentos de metatarsianos, diáfisis femoral derecha y dos fragmentos más del mismo fémur izquierdo ${ }^{20}$.

El relleno de la fosa, consecuencia del expolio, estaba formado por un escombro de abundantes mampuestos calizos muy fragmentados, trozos de tégulas de amplia curvatura y restos de revestimiento de mortero de cal y arena de cuyo perfil ligeramente curvo con improntas de cañizo se infiere una cubierta de falsa bóveda formada por materiales de poco peso. La presencia al exterior de una superficie horizontal de mortero de cal y arena de unos $5 \mathrm{~cm}$ de espesor x 1,40 m de largo x $0,90 \mathrm{~m}$ de ancho refuerza la excepcionalidad de esta tumba.

20 Pastor et al., op. cit., n. 16.
La mencionada plataforma sugiere la presencia de mensa para ritos fúnebres, algo totalmente inusual en las necrópolis de la Meseta, donde hay tumbas revestidas con cantos de río, tégulas o ladrillos, como, por ejemplo, las n. ${ }^{\text {os }} 34$ y 37 de la necrópolis norte de La Olmeda (Abásolo et al., 1997: 33-35), no comparables a la que nos ocupa. Solo la Tumba 5 de la necrópolis de Albalate de las Nogueras (Fuentes, 1989: 42) presenta un ligero parecido a esta de Almenara. Probablemente la sepultura, con cierta presencia arquitectónica y quizás algún indicador en superficie, llamaría más la atención, lo que pudo facilitar su saqueo o su destrucción intencionada.

\subsubsection{Tumba 10 (Figs. 2, 4, 5, 20 y 21)}

La fosa, de 2,40 $\mathrm{m}$ de longitud $\mathrm{x}$ 1,10 de anchura $\mathrm{x} 0,40$ de profundidad, está forrada con un muro perimetral de mampostería caliza de $20 \mathrm{~cm}$ de espesor que deja unas dimensiones internas de $2 \times 0,70 \mathrm{~m}$. A pesar de haber sido completamente expoliada, en la cabecera y en el lienzo septentrional se documentaron al excavar evidencias de la plancha de mortero y piedras calizas con la que se selló. También en su interior se han podido reconocer indicios del ataúd porque aún estaban in situ cinco de los clavos de cabeza circular que armaron los pies de la caja. Tras el robo, la tumba fue colmatada con tierra que incluía restos de calizas y de cantos rodados, así como fragmentos de tejas de amplia curvatura. La menor proporción de materiales edilicios deesterellenohabríaquerelacionarlaconelhechode que se tratase de una construcción más sencilla que la de la Tumba 9, con solo una cubierta horizontal de fábrica, a modo de losa, tal vez similar a la de 5 . 


\subsection{Una fosa inconclusa}

Paralela a la Tumba 6, hacia el $\mathrm{N}$ y a $1,90 \mathrm{~m}$ de distancia, se documentó un corte alargado de $1 \mathrm{~m}$ de largo x 0,60 de anchura que alcanzó una profundidad de $80 \mathrm{~cm}$ (Fig. 2). Por su posición estratigráfica y situación dentro de la necrópolis se relaciona con una fosa que no llegó a terminarse. Marcaría el abandono del uso de la necrópolis.

\subsection{Evidencias del expolio de la necrópolis}

El expolio de esta necrópolis es evidente en las Tumbas 7, 9 y 10, pero no se circunscribió solo a ellas. Tres fosas (Fig. 2) de perímetro alargado -de $1,60 / 2 \mathrm{~m}$ de longitud x $0,40 / 50 \mathrm{~m}$ de profundidad- en cuyo interior se ha identificado escombro -piedras calizas, trozos de mortero y fragmentos de amplias tejas curvas- muestran que los responsables del robo buscaron más sepulturas abriendo diferentes hoyos hacia el $s$ y SE. Aunque alguna no se ha podido excavar completamente, las tres comparten un parecido relleno de tierra con materiales constructivos; estos depósitos son similares a los que se documentaron en las Tumbas 9 y 10. de la hacienda. Además, dado que el análisis de los correspondientes contextos cerámicos ha hecho posible situar el abandono del edificio residencial de la villa a mediados del s. v y el final de algunas estructuras de habitación -Casa G- y de trabajo surgidas a su alrededor en las postrimerías de esa centuria (García-Merino y Sánchez-Simón, 2017: 175-180), cabría relacionar estas diez tumbas con los últimos habitantes de esa zona del asentamiento.

Solo conocemos datos antropológicos y paleopatológicos de nueve de las diez personas enterradas. Y dado que hay estudios o publicaciones en curso al respecto, bien poco es lo que podemos aportar por el momento sobre su caracterización en estos campos. Solo hay un infantil enterrado - Tumba 2- de unos 5 años de edad, que podría interpretarse como probable indicio del corto periodo de uso de la necrópolis. De población juvenil hay una muchacha de 15/16 ańos - Tumba 6-y un joven algo mayor, de 19/20 años -Tumba 5-. El resto de los individuos -dos mujeres en las Tumbas 1 y 3 , un hombre en la Tumba 7 y otros dos indeterminados en las Tumbas 8 y 9- llegaron a alcanzar la edad adulta, muriendo en rangos de edades estimadas entre 25 y 40 años, cifra que con los datos disponibles no parece que ninguno superase (Figs. 4 y 5).

\section{Consideraciones finales}

Esta necrópolis, la única hallada hasta el momento en este yacimiento de larga trayectoria habitacional, corresponde al último momento de su ocupación. La cronología más ajustada de los enterramientos es difícil de concretar más allá de su encuadre en la fase más avanzada de las necrópolis rurales postimperiales debido a sus características (Vigil-Escalera, 2015: 210). Por otra parte, el reducido número de inhumados -10-, la proximidad a las instalaciones de la villa y la escasez de ajuares permitirían atribuirla a un pequeño grupo, tal vez familiar, de trabajadores

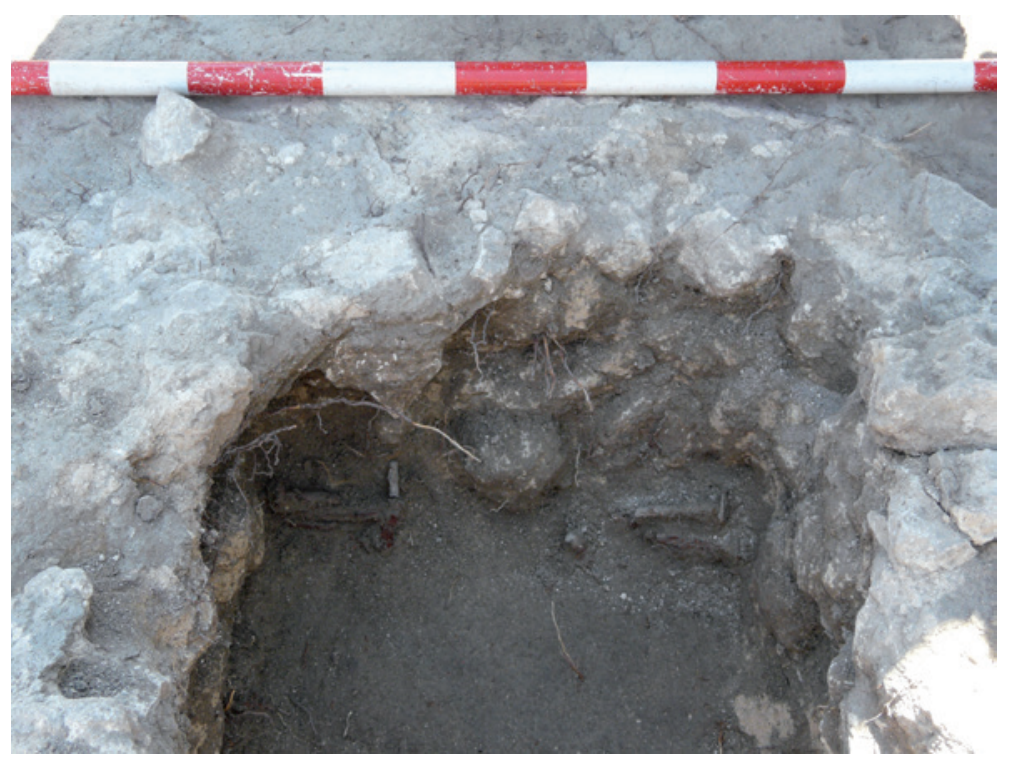

Fig. 21. Tumba 10: detalle de las puntas del ataúd en la zona de los pies. 
Respecto a la actividad en vida de los inhumados, muy poco es posible deducir: dos de las mujeres hilaban, como ponen de manifiesto los husos depositados en sus tumbas - las ruecas, que formarían pareja con ellos para el trabajo de hilado, serían quizás de madera por lo que no se habrían conservado-. La presencia de husos metálicos es frecuente en necrópolis tardorromanas y/o postimperiales (Vigil-Escalera, 2015: 215). Tres de los enterrados - Tumbas 1, 4 y 8 - muestran huellas de trabajo físico en su esqueleto. Otro de los difuntos -Tumba 8-, en este caso alofiso, presenta también marcadores de actividad que podrían relacionarse con un trabajo que conllevara una larga permanencia sentado con las piernas flexionadas. En cuanto al joven de la Tumba 5 , los objetos que le acompañaban, en particular la presencia del bote que con dudas podría considerarse un tintero, supondría, de ser así, que su dueño tuviera una actividad relacionada quizás con algún aspecto de la administración de la hacienda. Cabría, además, entenderla tal vez como una de las últimas evidencias de ese tipo de escritura en unos momentos en que ya se estarían utilizando las pizarras de contabilidad en el mundo rural (Martín-Viso, 2015: 296-297). En relación con esto procede señalar la presencia de algunos fragmentos ágrafos de lajas de pizarra, material alóctono en la zona, entre los escombros y las cerámicas en varias estructuras rústicas coetáneas de la Casa G, surgidas al exterior de la pars urbana de la villa, cuando esta se hallaba ya deshabitada por los dueños (García-Merino y Sánchez-Simón, 2017: 179, fig. 4).

No es fácil en una necrópolis identificar distintas fases de uso si no existe una superposición estratigráfica de los enterramientos. En este caso, gracias a la acción de expolio que afectó a las Tumbas 7, 9 y 10 y a la presencia de hoyos de rebusca al exterior del cementerio, hemos podido reconocer diferentes momentos de actividad a lo largo del s. v avanzado: su uso inicial como espacio para enterrar, el posterior saqueo de varias tumbas y, después, tres nuevos enterramientos. El expolio supuso la apertura de las tumbas existentes y la extracción de los ataúdes y de los cadáveres. No es posible determinar las razones del saqueo más allá de la intención de recuperar los ajuares o depósitos funerarios de las dos - Tumbas 9 y 10 - que debían presentar una singular entidad constructiva. Como resultado, los cuerpos -en estado de putrefacción o incluso ya esqueletizadosdebieron desmembrarse. En cuanto a los restos de los ataúdes que pudieran haber quedado, también se degradó su madera hasta desaparecer como pone de relieve el hecho de que en la Tumba 10 se haya podido reconocer mediante los clavos, aún in situ, la parte de los pies de la caja. Parte de los elementos metálicos de esos féretros se ha identificado descontextualizada en el relleno de las fosas de las Tumbas 4 y 6 (Figs. 4 y 5). Otro dato que parece reforzar la posterioridad de esas tumbas respecto a la acción de saqueo señalada es que, entre las tierras que las colmataban, se identificaron mampuestos calizos y trozos de ladrillos y de tejas de amplia curvatura que bien podían haber formado parte de las estructuras de la 9 y/o de la 10 (Figs. 4 y 5).

En las tumbas se aprecian ciertas diferencias en los rituales de enterramiento (Figs. 4 y 5), posiblemente con implicaciones cronológicas de pequeño alcance. Sin embargo, es difícil saber si esas diferencias - mayor simplicidad y ausencia de ajuar o depósito fúnebre o ritual- responden a una distinción de carácter social -siervos y libres- o se relacionan con cambios producidos en las costumbres funerarias por pequeña que sea la distancia temporal entre unas y otras puesto que plausiblemente la necrópolis se utilizaría solo en la segunda mitad del s. v.

Los cuerpos que se han conservado fueron colocados en decúbito supino y con evidentes indicios de amortajamiento deducibles de la posición de tibias y tobillos. Con ataúdes claveteados se enterraron los individuos de las Tumbas 1-3, 5, 8 y 10; seguramente también el de la 9 , aunque no han quedado pruebas de ello (Figs. 4 y 5). Las cajas se han reconocido por conservarse en su posición original las puntas una vez podrida la madera. La clavazón la formaban entre 16 y 23 clavos largos de hierro $-8,5 / 10 \mathrm{~cm}$ de longitud-. Por su distribución sabemos que los ataúdes estaban compuestos por cuatro tablas laterales - de 2,5 cm de grosor cada una- más la tapa y la base; para unir cada una de estas últimas se usaron cuatro puntas más, una por 
cada esquina. En algunos casos, se refuerzan con cantoneras en las esquinas y/o en los lados largos. Tipológicamente, esas puntas responden a tres modelos según la morfología de la cabeza: en forma de $\mathrm{T}$, circular y lateral. Ciertas cajas, las de las Tumbas 5 y 8 , fueron reforzadas en las esquinas con cantoneras. En cuanto a la madera de estos ataúdes, los análisis realizados de restos lígneos conservados en algunos clavos, revelan que era de pino ${ }^{21}$.

Los objetos que acompañaban al difunto (Figs. 4 y 5) se situaban al lado de la pierna derecha o a la derecha de los pies, claramente al interior del ataúd cuando este se ha podido identificar por la presencia de clavos. Todos los enterramientos que no habían sufrido la acción de los saqueadores, excepto el infante de la Tumba 2 y el alofiso de la 8 -ambos pudieron haber tenido objetos de material perecedero que por lo tanto no se han preservado- contaban con ajuar personal -los astrágalos y el huso, tal vez la caja de bronce y el instrumento de hierro- y con elementos propios del ritual fúnebre -recipientes cerámicos o de vidrio-.

En cuatro de las Tumbas -las 2, 3, 5 y 8- había, colocado a un lado de los pies, calzado de cuyas suelas se han recogido en torno a 80 tachuelas por individuo. Este tipo de zapato/sandalia se ha reconocido también en diversas necrópolis de ambas Mesetas (Vigil-Escalera, 2015: 209). Sobre su significado nos inclinamos a pensar que se trata de un elemento ritual y no de ajuar personal. Vigil-Escalera (2015: 210) considera que tenía que ser algo ligado "de forma especial al difunto" diferente de los elementos del resto del ajuar personal: adornos, broches, equipo de caza, etc. En las necrópolis meseteñas, si hay calzado, este aparece a uno o a ambos lados de los pies, junto a las tibias o incluso en la cabecera como en la Tumba 39 de La Olmeda (Abásolo et al., 1997: 157). En nuestra opinión, cuando el difunto estaba amortajado -como parece desprenderse de que las tibias estén juntas-, resulta difícil

21 Barrera, M. (2014): Informe de química: fragmentos de ajuar funerario de Almenara-Puras. Centro de Restauración de Bienes Culturales. Junta de Castilla y León. Informe inédito depositado en la JCyL en el Museo de las Villas Romanas de Almenara-Puras. entender el depósito de su calzado como elemento de ajuar personal. Por otra parte, el tamaño de las piezas, reconstruido a veces por la conservación de las suelas y la posición y número de las tachuelas, resulta poco acorde con la probable longitud del pie del difunto; así en La Olmeda Norte -Tumba 95, perteneciente a un individuo juvenil-el calzado, un ejemplar a cada lado de las tibias, según la reconstrucción realizada, tenia $27,5 \mathrm{~cm}$ (Abásolo et al., 1997: 114). También en la necrópolis de Almenara los zapatos que acompañaban a un niño de unos cinco años -Tumba 2- serían mucho más grandes que la talla de su pie por el número de tachuelas -81 recuperadas-. Por ello cabe pensar que la presencia de un calzado estándar acompañando al difunto podría estar relacionada en esa avanzada fase con creencias sobre el mundo de los muertos y tener un significado ritual para el paso al más allá.

Hay finalmente dos mujeres sin ataúd -0 , en todo caso, con él pero cuyas tablas podrían haberse ensamblado sin clavos- y sin calzado -Tumbas 4 y 6-, ambas enterradas después del expolio de las tumbas que se encuentran en el extremo sur de la necrópolis. Solo una de ellas -Tumba 4- contenía un sencillo ajuar: una pulsera de bronce y un huso de hierro (Figs. 4 y 5 ).

Hay que destacar la presencia de la Tumba 9 con una plataforma de mortero anexa -base de una mensa o superficie relacionada con ella- y estructura construida de cierta entidad; su tipo de cubrimiento le proporcionaría en superficie mayor presencia que el resto de las sepulturas, lo que pudo ser causa de un expolio temprano. Cabe pensar que debió de pertenecer a un miembro destacado de esa pequeña comunidad, lo que quizá propiciase la inhumación de otras personas en sus inmediaciones y, aunque solo se ha detectado una tumba muy próxima, la 7 -muy sencilla y de un varón adulto-, esa cercanía, excepcional en el conjunto estudiado, podría entenderse en tal sentido. Aparte de interpretaciones no demostrables, como que la relativa singularidad de la Tumba 9 apuntaría al carácter foráneo del difunto, quizás del Sur donde hay tumbas con cubiertas similares, el hecho neto es que en la Meseta no se conoce, por ahora, este tipo de estructura funeraria. 
Hay otras dos sepulturas también con ciertas particularidades formales que las distinguen (Figs. 4 y 5): la 5, con losa de mortero y fosa muy ancha-probable indicio de que originariamente pudo haberse concebido para ser revestida con un paramento pétreo-, y la 10, con pared de piedra e indicios de cubierta. Ambas junto a la 9 son tumbas que destacan respecto a las restantes, cuyas fosas tienen una anchura menor. A la luz de estas diferencias, se puede afirmar -aun con los escasos datos disponibles- que hay algunos individuos del grupo que se entierran en tumbas de una especial categoría y en ataúdes con puntas de cabeza circular y cantoneras de refuerzo, rasgo este último que también comparte el difunto de la Tumba 8. La distribución de estas sepulturas podría estar señalando distintas áreas dentro de la necrópolis, cada una de las cuales estaría reservada a un tipo diferente de inhumación: por un lado, las caracterizadas por una estructura más elaborada y con un tipo de ataúd reforzado y, por otro, las de una mayor simplicidad.

En conclusión, las diez tumbas parecen formar una pequeña necrópolis ocupada por gente que trabajaba en las tierras de la villa, no sabemos en qué régimen, si eran colonos, siervos o simplemente el grupo familiar del guardián de la hacienda, cuando el edificio señorial estaba abandonado por sus dueños, ya en tiempos muy avanzados del s. v, tiempos de cambio hacia un mundo muy diferente.

\section{Bibliografía}

Abásolo, J. A.; Cortes, J. y Marcos, F. J. (2004): Los recipientes de vidrio de las necrópolis de La Olmeda. Palencia: Diput. Prov. de Palencia.

AbÁsolo, J. A.; Cortes, J. y Pérez, F. (1997): La necrópolis norte de La Olmeda (Pedrosa de la Vega, Palencia). Palencia: Diput. Prov. de Palencia.

Abásolo, J. A.; Cortes, J.; Pérez, F. y Vighi, A. (1984): Excavaciones en el yacimiento de La Morterona, Saldaña (Palencia). Palencia: Diput. Prov. de Palencia.

Aceituno, F. J. y Lalinde, V. (2011): “Análisis de almidones de la muestra TSHT. Yacimiento la Calzadilla (Valladolid)", Zephyrus, LXVIII, pp. 252-255.
Alonso, J.; Jerez, J. M. y Sabio, R. (2014): "Instrumentos de escritura en Hispania". En Bustamente, M. y Bernal, D. (eds.): Artifices idóneos: artesanos, talleres y manufacturas en Hispania. Madrid: csic, pp. 169-189.

Alonso, J.; Sabio, R. y Jerez, J. M. (2019): “Tinteros de bronce romanos de Augusta Emerita", Archivo Español de Arqueología, 92, pp. 251-269.

Campillo, D. (2001): Introducción a la paleopatología. Barcelona: Edit. Bellaterra.

Eckardt, H. (2018): Writing and Power in the Roman World. Literacies and Material Culture. New York: CUP.

Fuentes, A. (1989-1990): "Los vidrios de las 'necrópolis de la meseta'. Ensayo preliminar de clasificación", Cuadernos de Prehistoria y Arqueología de la Univ. Autónoma de Madrid, 17, pp. 169-202.

Fuentes, A. (1990): La necrópolis tardorromana de Albalate de las Nogueras (Cuenca) y el problema de las denominadas 'necrópolis del Duero'. Cuenca: Diput. Prov. de Cuenca.

García-Merino, C. y SÁnchez-Simón, M. (2011): "Una tumba femenina con ajuar de la villa romana de Almenara de Adaja (Valladolid)", Zephyrus, LXviII, pp. 239-255.

García-Merino, C. y SÁnchez-Simón, M. (2015): La Villa romana de Almenara de Adaja-Puras. A través de los archivos del tiempo. Valladolid: Diput. de Valladolid.

García-Merino, C. y SÁnchez-Simón, M. (2017): El final de la villa de Almenara de Adaja-Puras. Los contextos cerámicos. Madrid: Edic. La Ergástula.

Martín Viso, I. (2015): "Huellas del poder: pizarras y poblados campesinos en el centro de la península ibérica (siglos V-VII)", Medievalismo, 25, pp. 285-314.

Moreda, F. J.; Vilar, S.; Serrano, R. y Carral, R. (2011): "La necrópolis tardorromana de la villa de 'El Vergel' (San Pedro del Arroyo, Ávila)”, Oppidum, 6-7, 2010-2011, pp. 141-184.

Vigil-Escalera, A. (2013): "Prácticas y ritos funerarios”. En Quirós, J. A. (ed.): El poblamiento rural de época visigoda en Hispania. Arqueología del campesinado en el interior peninsular. Documentos de Arqueología Medieval, 6. Bilbao: upv, pp. 259-288.

Vigil-Escalera, A. (2015): Los primeros paisajes altomedievales en el interior de Hispania. Registros campesinos del siglo quinto d. C. Documentos de Arqueología Medieval, 7. Bilbao: upv. 